\title{
Organizational agility: ill-defined and somewhat confusing? A systematic literature review and conceptualization
}

\author{
Anna-Theresa Walter ${ }^{1}$
}

Received: 3 June 2019 / Accepted: 3 April 2020 / Published online: 19 April 2020

(c) The Author(s) 2020

\begin{abstract}
Superior business performance is a central objective of any firm in an unpredictable environment. Organizational agility (OA) constitutes one option for prospering in this environment. Although research confirms a positive effect of OA on business performance, studies show conceptual imprecision. I systematically review and compile previous findings and provide a coherent view of OA. A search in three databases yielded a final sample of 75 articles. From a qualitative analysis, I identify four agility categories: agility drivers, agility enablers, agility capabilities, and agility dimensions. Based on findings from each category, I develop a conceptual map of OA that (i) connects the agility categories and clarifies how they work, and (ii) proposes a framework for the tasks and responsibilities of management within an agile organization. As part of the conceptualization, I also consider the business environment and the impact of an increased OA level. Viewed from a dynamic capability perspective, changing internal and external agility drivers necessitate the development of agility capabilities. These are realized by a specific set of interdependent enablers. Within this concept of an agile organization, management assumes various responsibilities, in particular, engaging in monitoring and decision-making functions. Conceptual clarity of OA at the organizational level facilitates a systematic development of agility research and provides guidance for practitioners. This article contributes to agility research by integrating insights from various research streams on OA. By highlighting the close ties to strategic management and the derivation of a model to agile management, this research also contributes to strategic management research.
\end{abstract}

Electronic supplementary material The online version of this article (https://doi.org/10.1007/s1130 1-020-00186-6) contains supplementary material, which is available to authorized users.

Anna-Theresa Walter

anna-theresa.walter@mailbox.tu-dresden.de

Extended author information available on the last page of the article 
Keywords Organizational agility $\cdot$ Business performance $\cdot$ Strategic management Agile management $\cdot$ Systematic literature review

JEL L200

\section{Introduction}

Attaining strong competitiveness and superior business performance constitutes a major challenge for firms, especially in a volatile business environment. Customer demands are becoming more dynamic (Vinodh et al. 2010b) and the frequency of environmental changes is increasing significantly (Ahlbäck et al. 2017). This leads to growing complexity and uncertainty in the market (Vinodh et al. 2010a), thus increasing competition (Vinodh 2010). Certain organizational capabilities can enable a company to respond appropriately to rapidly changing environmental conditions and to exploit these changes as business opportunities. In this context, Hatzijordanou et al. (2019) emphasized a high agility level as a rewarding capability when aimed at the quick exploitation of business opportunities. Meinhardt et al. (2018) confirmed the high impact of an increasingly dynamic business environment and suggest agility as a differentiation strategy.

In 1982, agility was first mentioned in the business context as 'the capacity to react quickly to rapidly changing circumstances' (Brown and Agnew 1982, p. 29). The original source (Brown and Agnew 1982) is quoted very rarely, though the understanding of agility corresponds to the current today: Organizational Agility (OA) expresses a company's set of capabilities for thriving and prospering in an unpredictable and rapidly changing environment (Vinodh et al. 2012a). Researchers widely believe that OA originated with the 1991 Lehigh Report of the Iacocca Institute, which was charged with identifying causes and potential solutions for the stagnant economic growth of the US manufacturing industry. OA, as an approach toward increasing competitiveness, was a sustainable outcome of the report. Regardless of the industry, managers agree that $\mathrm{OA}$ is a critical success factor that determines how competitive a company will be in today's volatile business environment (De Smet and Aghina 2015). In a recent survey on agility in organizations, the majority of respondents answered that one of their top priorities in strategic development was raising the organization's OA level (Ahlbäck et al. 2017). The effectiveness of OA strengthens its importance: $81 \%$ of participants in a recent survey noticed an increase in business performance with the introduction of agility in the company (Ahlbäck et al. 2017). Academic research confirms the positive effects of OA on business performance (Inman et al. 2011; Vickery et al. 2010). Studies reveal that organizations with strong agility capabilities generate revenues $37 \%$ faster, with a profit that is $30 \%$ higher than those of non-agile companies (Glenn 2009; Wang et al. 2014).

Although the intention to implement OA is widely spread and the research interest is high, a critical ambiguity regarding the concept remains in the research literature (Van Oosterhout et al. 2006). A lack of conceptual clarity is, unfortunately, 
widespread in organizational research and has far-reaching consequences (Podsakoff et al. 2016). A large number of definitions and prevailing disagreements about the OA concept have led to a lack of common understanding, which makes it difficult to build on previous research findings. The wide variety of perspectives on OA constitutes an example of critical differences in definition approaches. Among others, the most widespread and contrary views are of OA as either a 'paradigm' (e.g., Meade and Sarkis 1999; Zhang and Sharifi 2000) or a 'capability' (e.g., Bessant et al. 2001). Another existing approach attempts to conceptualize agility as a 'manufacturing strategy' (Zhang and Sharifi 2007, p. 352). Due to the fundamentally different perspectives on the main research object, which represents a major problem in the context of OA research, researchers do not speak the same language and, thus, the comparability of research results is limited (Podsakoff et al. 2016). This discrepancy appears to be a common problem in concept development, which Klein et al. (2009) confirmed in their review. These different perspectives require different measurement methods, which is why it is of utmost importance to develop a clear definition (Podsakoff et al. 2016). Therefore, in this article, I will first highlight the conceptual differences between approaches to OA, addressing the following research question: 'Which different perspectives exist on OA and which, according to our current knowledge, is suitable for a conceptualization?' The previous literature also shows an interchangeable use of 'agile' and similar terms such as 'flexible' (e.g., Monplaisir 2002). The blending of similar concepts leads to confusion and prevents a complete understanding of OA (Paixão and Marlow 2003). Researchers call this phenomenon concept proliferation, which means the emergence of differently named constructs with overlapping attributes or the use of different names for the same concept (Podsakoff et al. 2016). A fundamental cause of this is a lack of construct clarity and a lack of differentiation from similar or related constructs (Podsakoff et al. 2016). For a clear differentiation of OA and similar constructs, the elaboration of the unique feature of $\mathrm{OA}$, and, therefore, an increase in construct validity (Podsakoff et al. 2016), I initially differentiate OA from related concepts and provide a comprehensive overview.

Notably, the blending of OA categories is another pitfall. The use of the terms 'agility dimensions,' 'capabilities,' 'drivers,' and 'enablers' frequently occurred superficially and was mixed-up (Paixão and Marlow 2003; Zhang and Sharifi 2007) — and, thus, was taken out of the appropriate context. If a definition is ambiguous or not precise enough, measurement problems that inhibit further research can be a critical consequence (Podsakoff et al. 2016). For example, Vinodh et al. (2008) identified five agility enablers. Vinodh referred to the identified agility enablers in further research work (Vinodh 2010; Vinodh and Aravindraj 2012; Vinodh et al. 2012 b, a) but these are repeatedly described differently. When Vinodh et al. (2012b) mentioned 'five agility enablers' (p. 650), the same five points were also referred to as the 'five perspectives of agility' (Vinodh and Aravindraj 2012) or the 'five major drivers of agility' (Vinodh et al. 2012a). The same mixing of categories of OA takes place with regard to dimensions and objectives. These are described in Vinodh (2010) as 'major dimensions of AM [ed. note: Agile Manufacturing]' (p. 1016), while Vinodh et al. (2012a) spoke of 'major outcomes after the implementation of AM' (p. 6739). The repeatedly observed vague application of the terminology 
of the agility aspects perspectives, drivers, enablers, capabilities, and dimensions reveals a critical discrepancy in the definition and understanding of these terms. Even in recent literature, the application of terms is blurred and not uniform, leading to confusion among readers. This discrepancy is fatal for the operationalizing and measuring of OA in a consistent manner. In addition, research results focusing on specific aspects of OA can become very difficult to compile in order to form an overall picture. This makes it difficult to understand OA as a holistic concept. Up to now, few authors have dealt with a holistic conceptualization of OA. Previous proposed frameworks have had a strong focus on agility enablers (Gunasekaran 1998; Gunasekaran and Yusuf 2002; Sharp et al. 1999) or did not conceive of OA as an organizational concept, instead focusing on implementation processes (Gunasekaran 1998; Sharifi and Zhang 1999; Zhang and Sharifi 2000), and are limited to the manufacturing industry (Gunasekaran 1998; Gunasekaran and Yusuf 2002; Sharp et al. 1999; Vinodh et al. 2012a; Zhang and Sharifi 2007). Furthermore, agility dimensions are constantly mentioned as an agility category but are neglected in concepts. A clear definition, therefore, does not exist. In conclusion, inconsistent definitions of variables, neglecting a simultaneous consideration of all agility categories, and the resulting conceptual ambiguity, lead to discrepant results and difficulties in understanding. Continuing imprecision regarding the definition of agility categories (as in Vinodh et al. 2012a, b) and a lack of connection of these to an overall conceptual frame of OA create the need to develop a conceptual map based on recent research findings. A systematic review of the literature is a suitable method for addressing this gap by identifying agility drivers, enablers, capabilities, and dimensions as agility categories and compiling key findings in each category (Podsakoff et al. 2016). Therefore, through this article, I aim to shed light on the various attributes of OA, aggregate respective key findings, and relate them in a systematic and theoretically meaningful way to a holistic concept by answering the following research questions: 'What are the functions and roles of agility drivers, enablers, capabilities, and dimensions? How are the categories distinguishable, and what relationships exist?' The conceptualization of OA from a holistic perspective counteracts the current fragmentation of the research field. A clear conceptual definition can serve as an essential foundation for the further development of OA research (Podsakoff et al. 2016). Moreover, the theoretical concept can contribute to a successful application in practice, in that it increases management's understanding of agility in organizations and offers the opportunity to use this as a framework for targeted organizational development. Practicing managers could also develop a more comprehensive view of the various attributes of agility, which promises a more aware and targeted implementation of OA.

Considering OA as a specific dynamic capability, this paper evinces close ties to dynamic capability research, which highlights the role of strategic management (Schirmer and Ziesche 2010; Teece et al. 1997). Leadership and management in particular are critical success factors in the agile journey of a company (Ebrahim et al. 2018; Mahadevan et al. 2019). It is all the more alarming, it is precisely leadership and management that can be observed as a critical challenge during an agile transformation (McKinsey 2019). The results of a recent survey show the following three major obstacles in realizing $\mathrm{OA}$, each as part of inadequate management 
or leadership: cultural transformation, lack of leadership in general, and an unclear vision and implementation plan (Ahlbäck et al. 2017). Another survey on the state of agility identifies leadership style as the main difficulty during the implementation of agility (Business Agility Institute 2019). Research on implementation obstacles regarding OA agrees that a lack of management involvement is a critical challenge itself (Hasan et al. 2007; Potdar et al. 2017b). Potdar et al. (2017b) emphasized a lack of commitment, inadequate planning, and inappropriate strategies as sources of failure. Therefore, a closer look at the role of management in an agile organization in the context of this conceptualization is supposed to help overcome these challenges. This outlines another research question: 'What is management's role in an agile organization?' In this systematic literature review (SLR), I therefore analyze which roles and functions are attributable to management in an agile organization.

The paper is structured as follows. First, I provide a comprehensive overview of the relevant background literature. Here, I go into more detail on different perspectives on OA. I classify OA as a dynamic capability and provide an overview of existing definitions and effects found. Next, I present the core areas of literature analysis: the agility categories. In this context, I summarize the existing literature and explain the development of agility drivers, enablers, capabilities, and dimensions. This serves as the basis for the development of the conceptual map in section five. The following section delineates OA from other, similar concepts to provide a clear understanding of it. Subsequently, in section three, existing literature reviews on agility are presented and the necessity of this SLR is elaborated upon. Following this, I introduce the methodological approach in detail. The fifth section comprises the descriptive analysis of the data, followed by an extensive systematic content analysis. Key findings are summarized and the conceptual map is developed. Section six contains a conclusion and discussion of the findings. Finally, I outline limitations and critical issues for further research.

\section{Background literature}

\subsection{Perspectives on organizational agility}

The existence of various generic terms for OA indicates significant dissent in understanding the concept and show several different perspectives on OA. For construct clarity and further research, it is very important to recognize the different understandings and to agree on a unified view (Podsakoff et al. 2016). Sharp et al. (1999) considered OA as a 'management philosophy'. Bernades and Hanna (2009) referred to it as a 'philosophical approach'. Other researchers have referred to OA as a 'manufacturing paradigm' (e.g., Meade and Sarkis 1999; Narasimhan et al. 2006; VázquezBustelo et al. 2007), a 'performance capability' (e.g., Cho et al. 1996; Sambamurthy et al. 2003), a 'strategic capability' (e.g., Chakravarty et al. 2013), a 'dynamic capability' (e.g., Bessant et al. 2001; Chakravarty et al. 2013), a 'management strategy' (e.g., Paixão and Marlow 2003), and even a 'certain system propert[y]' (e.g., Giachetti et al. 2003). Narasimhan et al. (2006) illustrated fundamental differences between the most widespread umbrella terms, i.e., 'manufacturing paradigm' and 
'capability,' and the serious consequences of mixing them. If OA is seen as a paradigm of manufacturing, OA is treated as a 'system of practices' (Narasimhan et al. 2006, p. 441) and includes the firm's philosophy, values, and culture. Understanding $\mathrm{OA}$ as a paradigm is a representation of a high level of abstraction, with particular characteristics disappearing (Narasimhan et al. 2006). This extensive approach bears the risk of confusing definitions and mixing up 'what' with 'how' (Narasimhan et al. 2006). Not only is this a difficult foundation for further research into OA, but, also, differences between two similar concepts are not very clear. Thereby, distinguishing between two similar concepts becomes difficult. This can weaken discriminant validity (Podsakoff et al. 2016). Thus, the paradigm approach is considered too superficial (Narasimhan et al. 2006) and not suited to conceptualization.

Considering OA as a capability, performance capabilities are conceptually and clearly separated from practices (Narasimhan et al., 2006). This allows for a more precise definition of the terminology. In the following, with the aim of developing an applicable definition and a concept that reflects the application of OA in an organization, OA is considered a capability, as it is common in recent literature (Hazen et al. 2017; Lu and Ramamurthy 2011; Tallon and Pinsonneault 2011; Teece et al. 2016; Vickery et al. 2010). The following section describes OA as a dynamic capability in greater detail.

\subsection{Organizational agility as a dynamic capability}

Dynamic capabilities are 'the firm's capacity to innovate, adapt to change, and create change that is favorable to customers and unfavorable to competitors' (Teece et al. 2016, p. 18). Teece et al. (2016) regarded dynamic capabilities as a collection of processes, routines, knowledge, and entrepreneurial capabilities attributable to the management team. Looking at routines alone does not seem to be in line with the current highly competitive environment, as routines tend to adapt too slowly to changes (Teece et al. 2016). Therefore, the dynamic capabilities approach is useful in the context of agility. Further, entrepreneurial capability, as part of a dynamic capability, is critical to the harmonization of individual components and essential to the ability to anticipate developments and trends in a company's environment, which is an important feature of an agile organization. In conclusion, for the purpose of competitiveness, it is advantageous to consider the above-mentioned aspects of a dynamic capability together, as the set is 'not only scarce, but also often difficult to imitate' (Teece et al. 2016, p. 19). Teece et al. (2016) emphasized that firms with strong dynamic capabilities can assess the need for agility and implement it more easily and with less loss of efficiency.

Overby et al. (2006) differentiated dynamic capabilities from OA, as the dynamic capabilities-concept is more wide-ranging. OA can be realized by a 'specific subset' of dynamic capabilities (Overby et al. 2006, p. 121). Teece et al. (2016) defined $\mathrm{OA}$ as 'the capacity of an organization to efficiently and effectively redeploy/redirect its resources to value creating and value protecting (and capturing) higher-yield activities as internal and external circumstances warrant' (p. 17). Consequently, an agile organization can manage demand shocks and uncertainties and adapt its 
strategy accordingly (Teece et al. 2016). Lee et al. (2003) considered OA as a 'twodimensional' dynamic capability: an offensive entrepreneurial dimension and a defensive adaptive dimension. Therefore, an organization can operate agilely and successfully only if the two crucial dimensions of the dynamic capability of OA are well-developed. Building on this, Lee et al. (2015) conceptualized OA as a 'higherorder dynamic capability to configure and reconfigure organizational resources in response to the environment or emerging competitive realities' (p. 400). The integration of lower-order, functional capabilities facilitates new higher-order dynamic capabilities (here, OA), which, in turn, enable innovative competitive actions. This means that a combination of various methods enables the building, integration, and reconfiguration of internal and external resources with the aim of sustaining and improving the firm's competitiveness. Lee et al. (2015) concluded that organizations with high $\mathrm{OA}$ - and, thus, strong higher-order dynamic capabilities - are able 'to detect opportunities and threats, assemble the needed assets and capabilities to launch an appropriate response, judge the benefits and risks of initiating an action, and execute actions with competitive speed and success' (p. 400). OA as a specific dynamic capability is difficult to copy and not easily acquired by an organization (Teece et al. 1997). This creates a competitive advantage. In the following, OA is regarded as a specific dynamic capability that constitutes one option for prospering in a volatile, unpredictable, and uncertain environment (Teece et al. 2016).

\subsection{Definition of organizational agility and effects on performance}

Scientists offer various understandings of agility. The following table provides an overview of exemplary definitions. It also shows the characteristics of the business environment and the goal of agility (Table 1).

Previous definitions of OA have significant differences but shared characteristics of the construct are observable regarding the following aspects:

- OA is seen as a response to continual and unpredictable changes and is, therefore, particularly necessary and effective in a constantly changing, volatile, and unpredictable business environment (Iyer and Nagi 1997; Lu and Ramamurthy 2011; Sindhwani and Malhotra 2017; Teece et al. 2016; van Oosterhout et al. 2006; Vinodh and Aravindraj 2015; Yusuf and Adeleye 2002).

- A functional focus is on speed and responsiveness (Gunasekaran and Yusuf 2002; Lu and Ramamurthy 2011; Sambamurthy et al. 2003; Tallon and Pinsonneault 2011; Vickery et al. 2010; Zhang and Sharifi 2007).

- The main objective of OA is increased competitiveness (Bernardes and Hanna 2009; Bottani 2009; Cao and Dowlatshahi 2005; Giachetti et al. 2003; Lin et al. 2006; Vázquez-Bustelo et al. 2007; Vinodh et al. 2008; Yusuf and Adeleye 2002; Zandi and Tavana 2011).

Agile organizations strive for maintenance and enhancement of their competitive position (Bottani 2009; Gunasekaran et al. 2018) by rapid and efficient production of high-quality products and reduced costs (Bottani 2009; Cheng et al. 2000; 


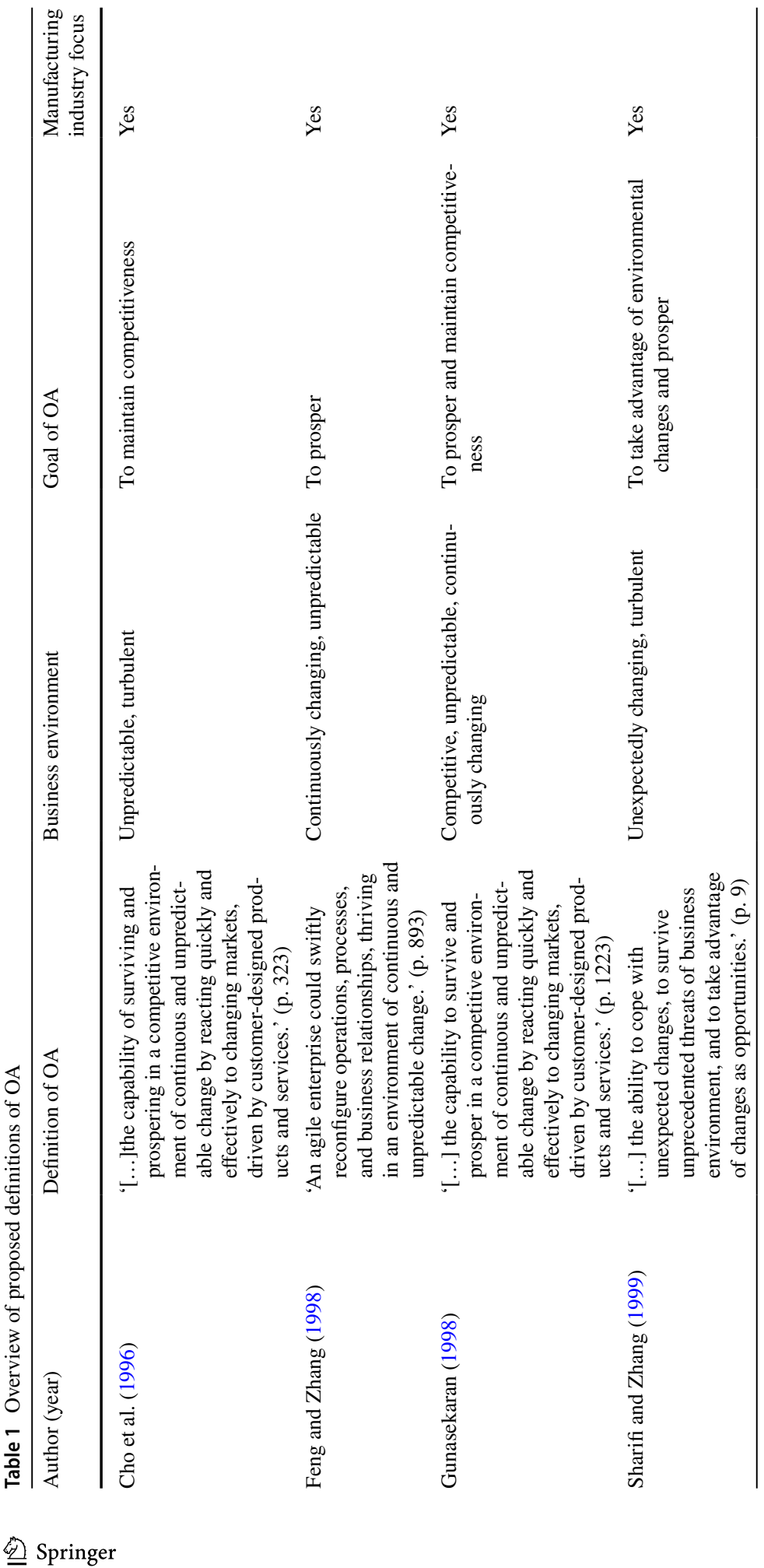




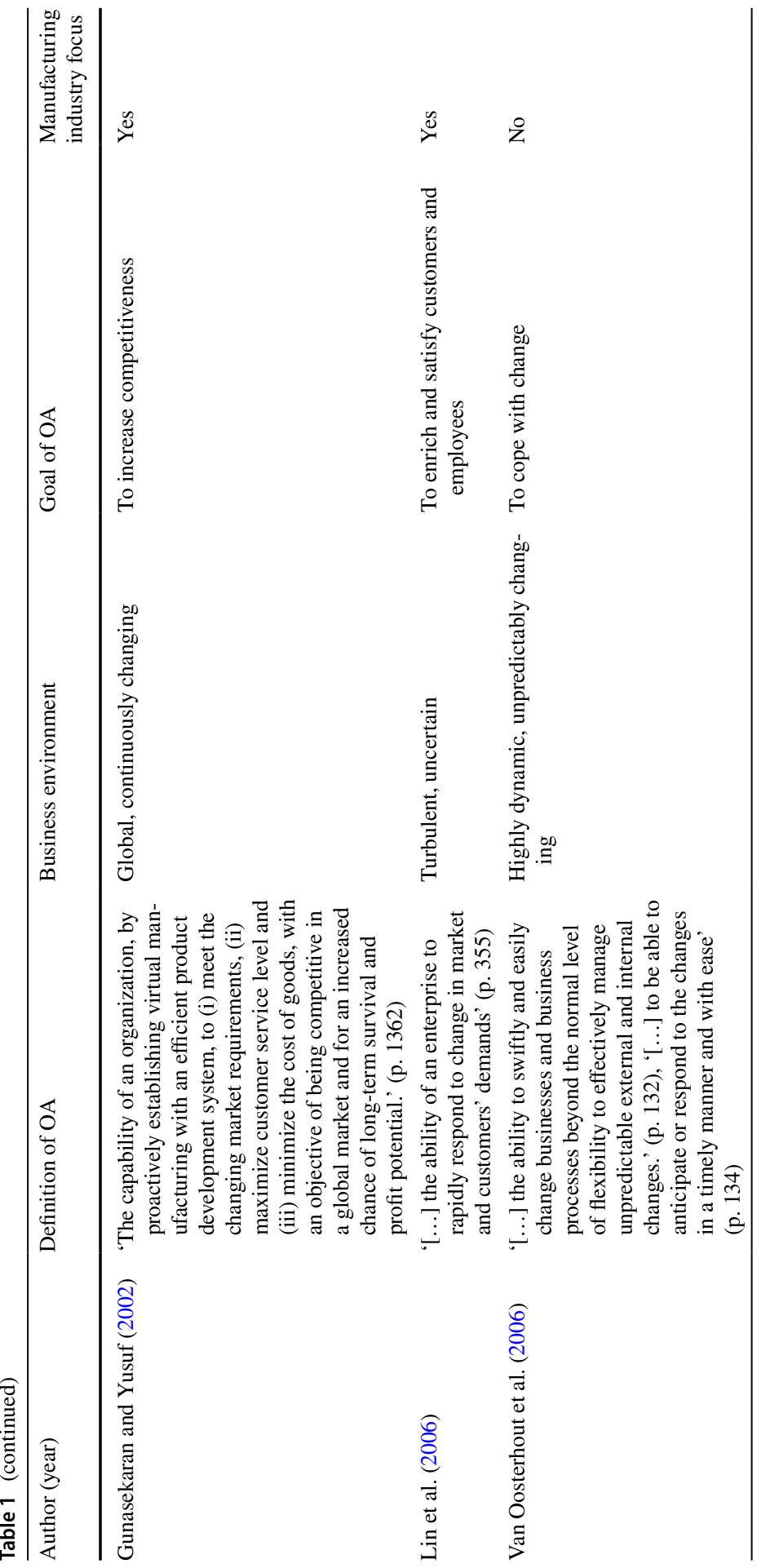




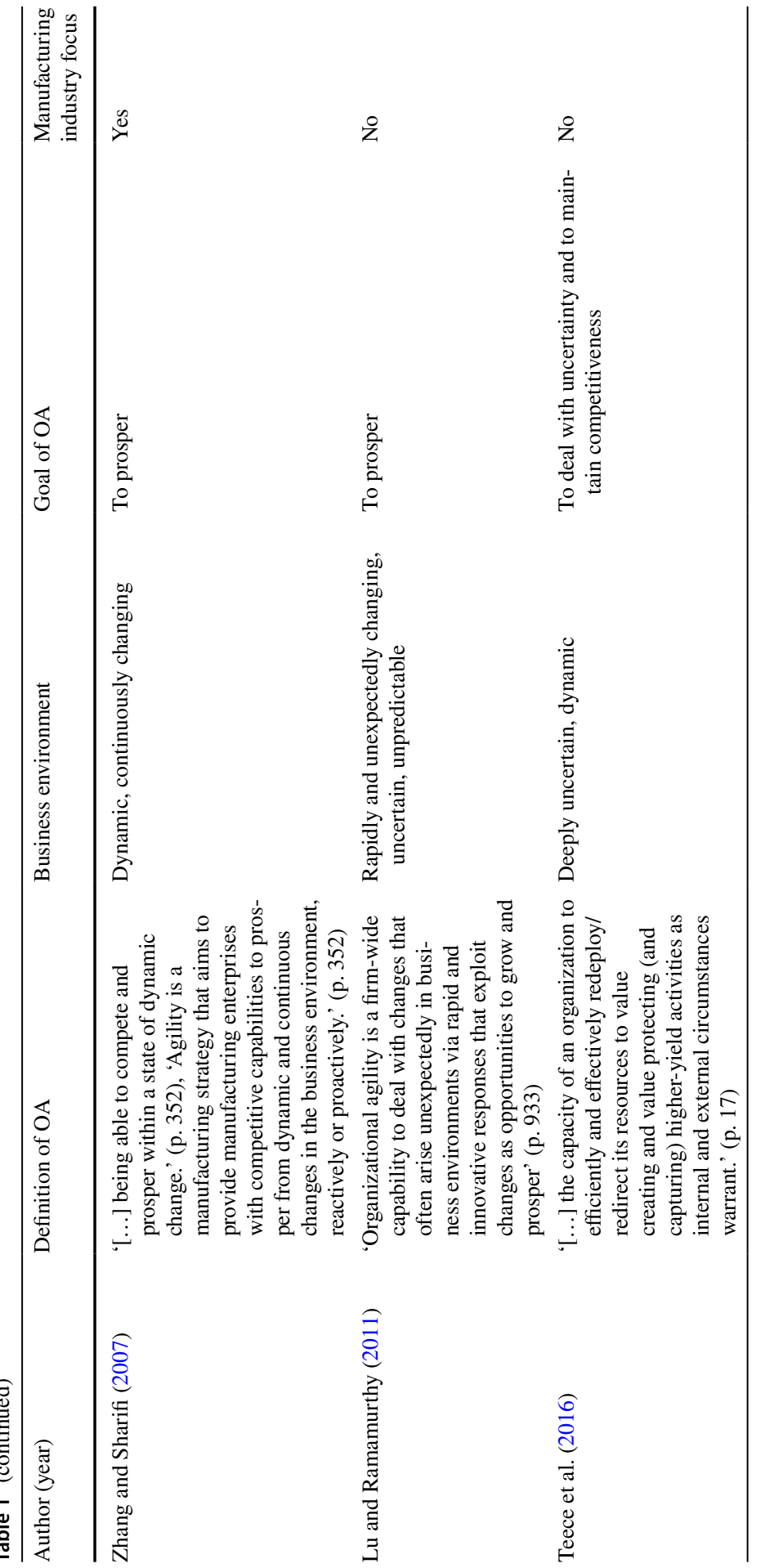




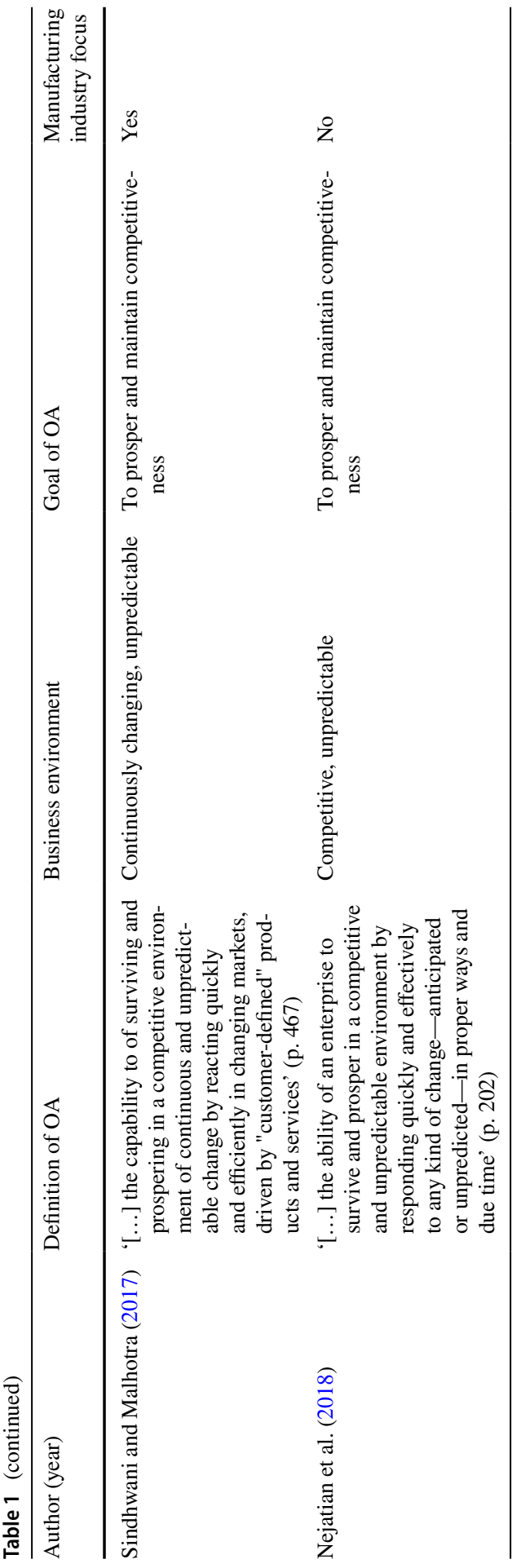


Lin et al. 2006; Mishra et al. 2014), customer satisfaction (Cao and Dowlatshahi 2005; Lin et al. 2006; Mishra et al. 2014), employee satisfaction (Lin et al. 2006), improved velocity in the introduction of new products (Sharifi and Zhang 2001), and the elimination of non-value-adding processes (Lin et al. 2006; Mishra et al. 2014). Additional frequently mentioned aims of OA are increased performance (Narasimhan et al. 2006; Wang et al. 2014), profitability (Chakravarty et al. 2013), and an increase in market share (Lin et al. 2006; Mishra et al. 2014). Vázquez-Bustelo et al. (2007) added environmental objectives. Multiple studies support OA's positive impact on a firm's performance (Hazen et al. 2017; Inman et al. 2011; Tallon and Pinsonneault 2011; Vickery et al. 2010; Wang et al. 2014; Yusuf and Adeleye 2002). Vázquez-Bustelo et al. (2007) found that a higher level of OA has a positive impact on operational, financial, and market performance through improved manufacturing strength.

\subsection{Categories of organizational agility}

In the following, I systematize the core areas of OA to classify the key findings of the reviewed literature. The categories presented here are necessary properties that are an essential part of the OA concept (Podsakoff et al. 2016). The subsequent systematic content analysis focuses primarily on the definition of the individual agility categories within the reviewed papers (Randolph 2009). This establishes the basis upon which to present the findings in a systematic and meaningful way. The developed conceptual map is based on the original framework of Sharifi and Zhang (1999), which is expanded; individual categories are enriched with new insights. Vinodh (2010) noted that 'the drawback in this work is that there is a need for improvement of the agility model's comprehensiveness' (p. 3). Yet, the concept is considered good preparation for companies to deal with uncertain and complex situations (Vinodh 2010) and provides a good foundation for the theoretical concept derived in chapter five. Sharifi and Zhang (1999) have studied the concept of agility in the manufacturing industry in depth and developed a methodology for assembling and understanding the concepts of agility in order to achieve agility in a company. An empirical study was then carried out to verify the developed methodology. The results of the study are reported in detail, and the conceptual model is explained, in Zhang and Sharifi (2000). Their concept consists of three interacting core areas: agility drivers, agility capabilities, and agility providers (Sharifi and Zhang 1999; Zhang and Sharifi 2000). These are the starting points for analyzing the relevant literature and, thus, for systematizing the key findings.

Agility drivers constitute environmental changes that put organizations in a new, vulnerable position and necessitate searching for competitive advantages. Statements and information identified as 'driving forces for agility' (Zhang and Sharifi 2007, p. 353) are associated with this core area.

Agility capabilities are specific abilities for providing the required power and competence to react to changes; they include responsiveness, competency, flexibility, and speed. Zhang and Sharifi (2000) described agility capabilities as 'essential capabilities that the company needs in order to positively respond to and take 
advantage of the changes' (p. 498). Lin et al. (2006) denoted agility capabilities as 'vital abilities that would provide the required strength to make appropriate responses to changes taking place in its business' (p. 358). Thus, agility capabilities represent the company's 'fitness' to handle changes and uncertainties (Lin et al. 2006, p. 356). In this core area, agility attributes appear as a synonym for agility capabilities (Bottani 2009; Nejatian et al. 2018).

Agility enablers describe methods, tools, practices (Sharifi and Zhang 1999) and crucial technologies facilitating OA (Gunasekaran 1998; Lin 2004; van Oosterhout et al. 2006). Agility enablers are utilized as leverage (Nejatian et al. 2018) at multiple organizational levels (Sharifi and Zhang 1999) and enable the realization of agility capabilities (Sharifi and Zhang 2001). This core area contains information about the above points of interest and is also described in the literature as agility providers (Lin et al. 2006; Zhang and Sharifi 2000, 2007) or agile practices (Bessant et al. 2001; Vázquez-Bustelo et al. 2007).

In addition, I consider agility dimensions as part of the analysis. The use of the terminology 'agility dimensions' is contentious and inflationary; thus, a precise definition of the core area is difficult. The contents of this core area have two things in common. One is the naming. The other is the goal of structuring agility in an organization with regard to operationalization. This means determining which dimensions of the organization must be agile to achieve organizational agility at a higher level.

In this article, the identified core areas of OA are summarized as agility categories. Thus, the conceptual map contains the four agility categories: agility drivers,

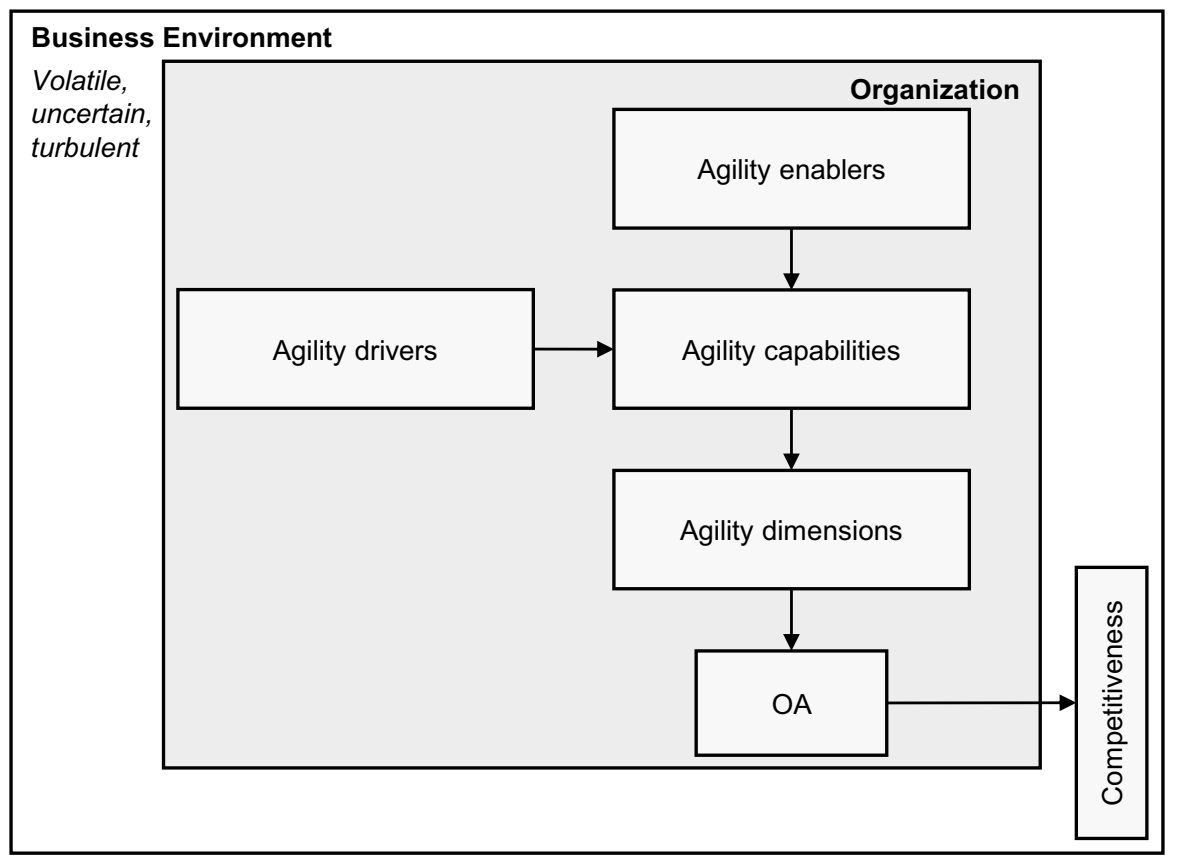

Fig. 1 Basic framework-OA concept development 
agility enablers, agility capabilities, and agility dimensions. Figure 1 provides a simplified overview showing the agility categories and their relationships with each other. The agile organization is surrounded by a volatile, uncertain, and turbulent business environment. Agility drivers induce the need for agility capabilities of the organization. These are realized by agility enablers. Agility capabilities are implemented in various agility dimensions, resulting in an overall enhanced organizational agility level. An increased OA level of the organization can contribute to an increase in competitiveness.

The key findings and critical developments, over time, of each agility category are now presented consecutively. Therefore, the following subchapters address the second research question with regard to the definition and delineation of the individual agility categories. Based on this, the results are summarized in chapter 5.3, set in relation to each other, and aggregated into a holistic concept.

\subsubsection{Agility drivers}

Until 2001, the focus was exclusively on external agility drivers, with an emphasis on customer-driven agility drivers. Then, researchers began regarding internal agility drivers as well. Eisenhardt and Martin (2000), who more closely investigated dynamic capabilities, supported this view, arguing that the competitive advantage of a firm in a high-velocity environment can be threatened internally as well as externally. In the following, findings are classified by the following types of environments: external changes only, external changes focused on customers, and external and internal changes.

Most researchers have confined agility drivers to the external environment. External changes occur continuously and unpredictably (Sharifi and Zhang 1999; Lu and Ramamurthy 2011) and lead to a highly competitive environment (Gunasekaran 1998) at a high frequency (Cao and Dowlatshahi 2005; Giachetti et al. 2003; Gunasekaran 1998; Mishra et al. 2014; Zhang and Sharifi 2000). Market changes, technology changes, and globalization are agility drivers that exemplify the external environment (Aravindraj et al. 2013; Cheng et al. 2000; Feng and Zhang 1998; Ganguly et al. 2009; Gunasekaran 1998; Gunasekaran et al. 2018; Quintana 1998). A notable number of researchers regard changes in customer demand as a driver of OA (Coronado Mondragon et al. 2002; Guisinger and Ghorashi 2004; Katayama and Bennett 1999; Sieger et al. 2000; Vickery et al. 2010). A high customer orientation in the agile setting could justify the approach.

In 2001, Sharifi and Zhang (2001) and Bessant et al. (2001) started considering internal and external environments. These are characterized by unpredictability (van Oosterhout et al. 2006) and potential disruptiveness (Overby et al. 2006). Van Oosterhout et al. (2006) identified fierce price competition and declining margins as the most significant agility drivers. The following table summarizes previously identified external and internal agility drivers and provides a selection of references (Table 2).

Sharifi and Zhang (2001) introduced an alternative classification of agility drivers and assigned changes to the marketplace, competition, customer requirements, 


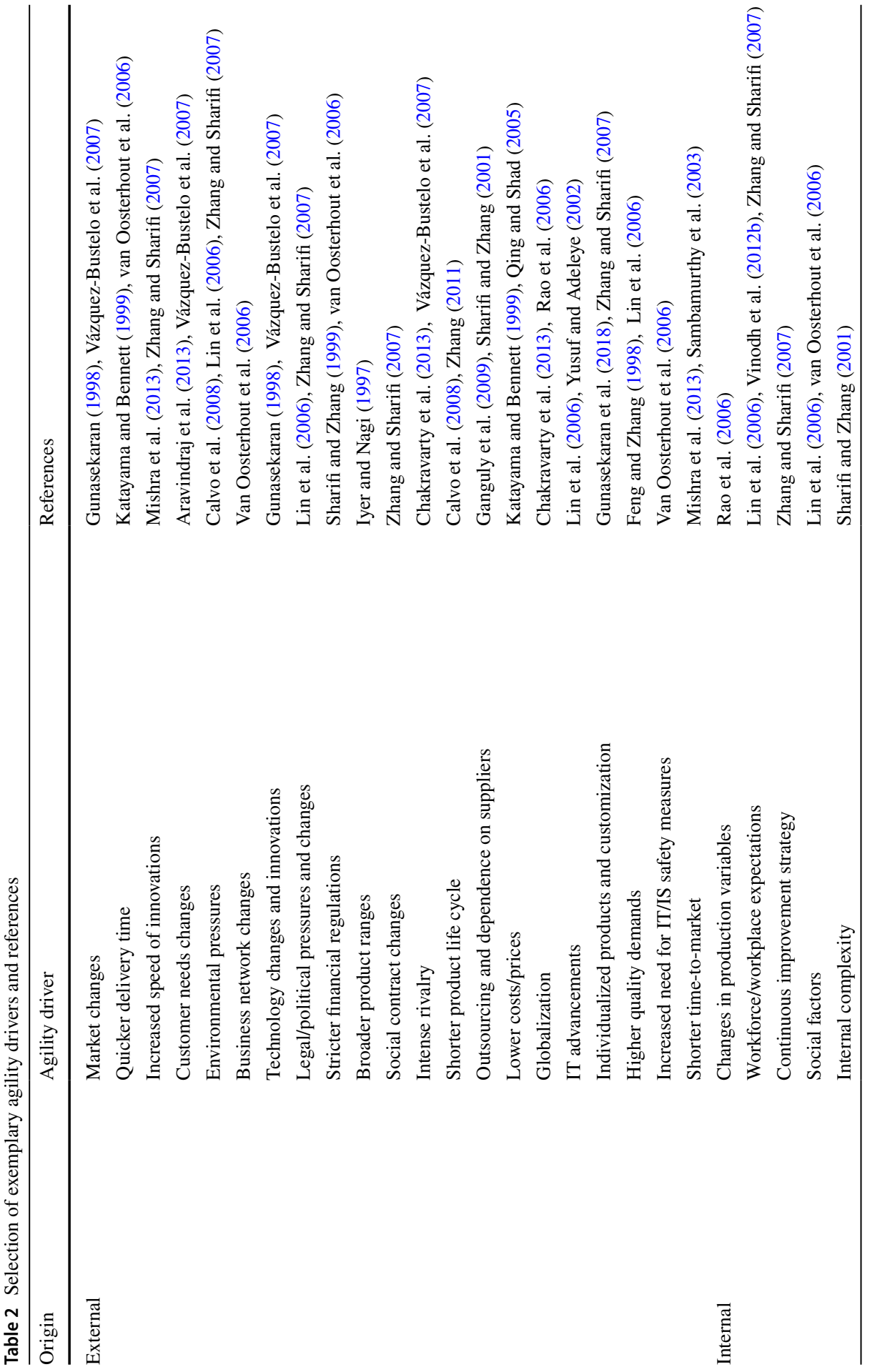




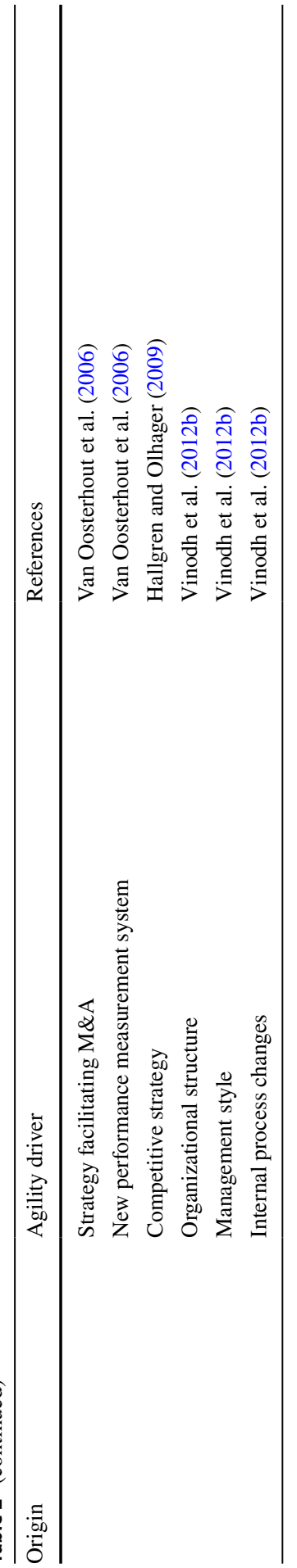


technology, social factors, suppliers, and internal complexity. Lin et al. (2006) grouped agility drivers as social/legal changes, business network changes, competitive environment changes, customer need changes, technology, and internal changes.

\subsubsection{Agility enablers}

Gunasekaran (1998) identified seven key enablers: virtual enterprise formation tools and metrics; physically distributed manufacturing architecture and teams; rapid partnership-formation tools and metrics; concurrent engineering; an integrated product, production, and business-information system; rapid prototyping tools; and electronic commerce. Sharp et al. (1999) added a focus on core competencies; a multi-skilled, flexible, and empowered workforce; continuous improvement and change and risk management; and information technology. The following enablers were also identified: the use of internet-based and advanced technology, the modularization of products, cross-functional integration, a culture of market orientation, the improvement of supplier relationships, customized manufacturing, service management, the active support of top management, a supportive organizational structure, optimal manpower and machine utilization, pull production, optimal inventory, and an agile strategy (Brown and Bessant 2003; Cheng et al. 2000; Guisinger and Ghorashi 2004; Lin 2004; Sindhwani and Malhotra 2017).

In literature addressing agility enablers, a special emphasis is placed on information technology, information systems, and virtual enterprises (Gunasekaran and Yusuf 2002). Several authors have identified IT as a significant agility enabler (Cao and Dowlatshahi 2005; Coronado Mondragon et al. 2004; Guisinger and Ghorashi 2004; Gunasekaran et al. 2018; Lee et al. 2015). Van Oosterhout et al. (2006) regarded IT as having either an enabling or an impeding effect and, therefore, emphasized its special meaning in an agile setting. Cao and Dowlatshahi (2005), Guisinger and Ghorashi (2004), Paixao et al. (2003), and Sieger et al. (2000) highlighted virtual enterprises and partnerships as agility enablers. While focusing on core competencies, an agile organization can compensate for its own weaknesses by taking advantage of the strengths of others to realize market opportunities (Sieger et al. 2000). Cooperation between organizations is regarded as a must-have criterion; realizing OA to its fullest requires cooperation (Gunasekaran et al. 2018). Consequently, the special emphasis on virtual enterprises as agility enablers becomes plausible. Lin et al (2006) referred to the integration of applied enabler and synchronization as the 'most important point' (p. 357) with the aim of transforming the applied agility enabler into strategically advantageous capabilities.

There are several frameworks for subdividing agility enablers. Bessant et al. (2001), Lin et al. (2006), and Meade and Sarkis (1999) assigned agility enablers to four groups, aimed at 'leveraging the impact of people and information' (p. 242), 'mastering change and uncertainty' (p. 242), 'enriching the customer' (p. 242), and developing collaborative relationships 'to enhance competitiveness' (p. 242). Van Oosterhout et al. (2006) identified six categories: business network governance, business network architecture, information technology, organization governance, organization architecture, corporate culture, and workforce. Vázquez-Bustelo et al. (2007) distinguished between practices related to HR, the application of advanced 
design, manufacturing, and administrative technologies related to internal and external structures and relations, product development and processes aimed at concurrent engineering, and practices relating to the knowledge management system. Zhang and Sharifi (2007) identified six groups of agility enablers that must adapt to develop an agile organization: relationships with supplier, customer, and competitors, technology, integration, organization, customer relationships, and information systems. Vinodh et al. (2008) divided agility enablers into five subclasses and provided illustrative criteria for each subclass. According to them, OA can be achieved by focusing on the following enabler subclasses: organizational structure enabler, manufacturing management enabler, workforce enabler, technology enabler, and manufacturing strategy enabler (Vinodh et al. 2008). Aravindraj et al. (2013), Vinodh and Aravindraj (2012), and Vinodh et al. (2010a) identified five major enablers: management responsibility agility, manufacturing management agility, workforce agility, technology agility, and manufacturing strategy agility.

\subsubsection{Agility capabilities}

The systematic review of previous literature reveals four generic agility capabilities that provide a basis for several researchers (Lin et al. 2006; Sharifi and Zhang 1999, 2001; Zhang and Sharifi 2000, 2007). Major agility capabilities are responsiveness, competency, flexibility, and speed. Sharifi and Zhang (1999) provided a proper definition of each capability and enumerated sub-capabilities. Responsiveness is defined as 'the ability to identify changes, respond rapidly to changes either reactively or proactively, and recover from changes' (Sharifi and Zhang 1999, p. 17). The respective sub-capabilities are sensing, perceiving and anticipating changes, an immediate reaction to changes, and recovering from changes. Sharifi and Zhang (1999) defined an organization's competency as 'abilities that provide a company with productivity, efficiency, and effectiveness in achieving its aims and goals' (p. 17). Through high competence, an organization is able 'to operate efficiently, produce high-quality and high-performance products, deliver on time, innovate, and manage core competency' (Zhang and Sharifi 2007, p. 354). To develop the respective capability, Sharifi and Zhang (1999) identified the following sub-capabilities: strategic vision; appropriate technology or sufficient technological capability; products/service quality; cost-effectiveness; high rate of new products introduction; change management; knowledgeable, competent, and empowered people; operations efficiency and effectiveness (leanness); co-operation (internal and external); and integration. The agility capability flexibility is defined as 'the ability to carry out different work and achieve different objectives with the same facilities' (Sharifi and Zhang 1999, p. 18) and includes multiple types of flexibility: product volume flexibility, product model/configuration flexibility, organization and organizational issues flexibility, and people flexibility. The fourth fundamental agility capability, speed, is 'the ability to carry out tasks and operations in the shortest possible time' (Sharifi and Zhang 1999, p. 18). According to Sharifi and Zhang (1999), this is realized by three sub-capabilities. The first is quickness in new products' time-to-market, while the second is quickness and timeliness in product and service delivery. Equally important is the third 
sub-capability, i.e., quickness in operations (short operational lead times). Zhang and Sharifi (2007) extended the list by adding the capabilities of proactiveness, focus on the customer, and partnership. Proactiveness is the organization's ability to behave anticipatorily toward threats and market opportunities. Partnership capability enables the building of concrete relationships with suppliers and partner organizations. Gunasekaran and Yusuf (2002) agreed with the 'traditional' agility capability approach but emphasized that OA should not be built solely on responsiveness and flexibility; rather, they said, it should also focus fundamentally on cost-effectiveness and high-quality products and services (Gunasekaran and Yusuf 2002).

Contrary to previous approaches, Lee et al. (2015) derived another set of relevant agility capabilities from previous literature: proactiveness, radicalness, responsiveness, and adaptiveness. Proactiveness constitutes forward-looking anticipation and responsiveness in order to seize new market opportunities ahead of competitors (Lee et al. 2015; Lumpkin and Dess 1996; Miller and Friesen 1983). The organization's ability to 'initiate radical strategic movements by implementing new business models to penetrate new markets' (Lee et al. 2015, p. 405) is labeled radicalness (Lee et al. 2015; Miller and Friesen 1983; Zahra and Covin 1995). Responsiveness enables a quick response to opening market opportunities caused by changes in customer demand or the environment (Hult et al. 2005; Lee et al. 2015; Tracey and Vonderembse 1999). Adaptiveness relates to business models and includes keeping pace with best practices on the market (Jarrar and Zairi 2000; Lee et al. 2015; Rindova and Kotha 2001; Subramaniam and Youndt 2005).

Overby et al. (2006) derived two key components of OA: sensing change and responding to it. The sensing ability enables the firm to recognize "competitor's actions, consumer preference changes, economic shifts, regulatory and legal changes, and technological advancements' (Overby et al. 2006, p. 121). Enabling capabilities are, for example, market intelligence, government relations, legal expertise, research and development, and information technology. The responding ability offers three response options that vary in their scopes: a complex move, a simple move, or no move (Overby et al. 2006 according to Ferrier et al. 1999). The third option is calculated inactivity that demonstrates a firm's ability 'to be agile but not necessarily display its agility at every opportunity’ (Overby et al. 2006, p. 124).

In comparing diverse approaches regarding agility capabilities, a particular focus on responsiveness and speed becomes obvious. Zhang and Sharifi (2007) identified responsiveness as the 'most frequently cited capability in the literature' (p. 354). Even more radically, Zhang and Sharifi (2000) labeled responsiveness as 'the essential capability for any organisation which needs to be agile' (p. 354). Competency, flexibility, and speed are necessary prerequisites for gaining responsiveness (Zhang and Sharifi 2000). Lin et al. (2006) agreed about the importance of responsiveness in all areas of a company (strategy, technology, HR, business processes, and facilities). The analysis of the development of agility capabilities shows a shifting scope of responsiveness. In the beginning, the focus is on reacting to environmental change. Over time, researchers realized the equal importance of perceiving and recognizing change as a crucial part of responsiveness (Huang et al. 2014; Overby et al. 
2006). Neglect of the recognition component is reckless because it is an indispensable prerequisite and basis for reacting to change. Companies should recognize market changes before their competitors do in order to exploit the market opportunity, which is a major advantage of a highly agile company.

\subsubsection{Agility dimensions}

The least clear and most controversial category is that of agility dimensions. In this matter, Zhang and Sharifi (2007) unfavorably mixed agility dimensions and agility capabilities. A confusing usage of the term 'agility dimensions' and a lack of a lucid meaning remain worthy of criticism. In addition to the 'classical' approach, alternatives are introduced below.

Notable authors (e.g., Coronado Mondragon et al. 2002, 2004; Eshlaghy et al. 2010; Iyer and Nagi 1997; Meade and Sarkis 1999; Paixão and Marlow 2003; Potdar et al. 2017a; van Oosterhout et al. 2006; Yusuf and Adeleye 2002) referred to the 'classical' approach of agility dimensions, the origin of which is the practitionerbased Lehigh Report (Industry Team and Facilitators 1991). Although various articles refer to the particular source, an explicit meaning of agility dimensions does not become apparent and the function remains unclear. In the early years of OA research, the dimensions are also referred to as 'competitive foundations' (Sharp et al. 1999, p. 160), which are understood as being 'interrelated and overlapping' (Sharp et al. 1999, p. 160) principles. These are to be pursued at the same time and can therefore contribute to an improvement of the manufacturing company (Sharp et al. 1999). Goldman et al. (1995) classified four dimensions as competitive foundations or 'underlying principles' (Katayama and Bennett 1999, p. 44). One is 'mastering change and uncertainty' (control dimension), which expects a constantly changing, demanding environment that calls for change. Another, 'customer enrichment' (output dimension), means that organizations must respond rapidly to consumer demand with customized, high-quality products. The third and fourth dimensions- 'cooperating to enhance competitiveness' (input dimension) and 'leveraging the impact of people and information' (mechanism dimension) - represent the realization of OA by the integration of technology and HR through an adaptable organizational structure, an appropriate management style, and internal and external cooperation (Industry Team and Facilitators 1991). Sharp et al. (1999) regarded the following major points as competitive foundations: a continuously changing environment, a rapid response with customized, high-quality products, and social responsibility.

Alternatively, scholars have classified specific parts of an organization as dimensions. Bessant et al. (2001) described 'four major dimensions' of OA as follows: an agile strategy, agile processes, agile linkages, and agile people. Monplaisir (2002) subdivided OA into the key dimensions of management, technology, and workforce, each with its own characteristics that can be realized through the application of various enabling systems. According to Vinodh and Aravindraj (2012), agility should be integrated into technologies, skills, and external cooperations. Brown and Bessant (2003) extended these pillars by including strategies, corporate culture, and business practices. Lin et al. (2006) did not title the organization areas agility dimensions 
but their segmentation aligns with those of the above-mentioned authors. To be able to respond quickly and effectively to changing market demands, all corporate sectors require agility enablers (Lin et al. 2006). Therefore, OA should be developed in strategies, technologies, people, business processes, and facilities (Lin et al 2006). Vázquez-Bustelo et al. (2007) regarded OA as a 'multidimensional concept' (p. 1305) in five dimensions: agile human resources, agile technologies, value chain integration, concurrent engineering, and knowledge management.

Another approach is the differentiation regarding various types of OA. Sambamurthy et al. (2003) classified three different types of OA: customer agility, partnering agility, and operational agility. Zandi and Tavana (2011) divided OA into three parts: strategic agility, operational agility, and functional agility. Several agility criteria facilitate agility in each dimension. Agility criteria are individual and, thus, differ from company to company (Zandi and Tavana 2011). Lu and Ramamurthy (2011) distinguished between market-capitalizing agility and operational-adjustment agility. Both imply a constant readiness for change. According to Tallon and Pinsonneault (2011), agile organizations must be able to 'easily and quickly change their strategy' (p. 473) regarding customer responsiveness, business partnerships, and operations. This requires customer agility, business-partnering agility, and operations agility (Tallon and Pinsonneault 2011). Chakravarty et al. (2013) conceptualized OA, with reference to Overby et al. (2006) and Lee et al. (2003), as a twodimensional dynamic capability composed of an entrepreneurial offensive part and an adaptive defensive part. Aligning with Overby et al. (2006), Huang et al. (2014) regarded $\mathrm{OA}$ as an organizational capability comprising a sensing component and a responding component. Subordinately, five major agility dimensions exist: management agility, product-design agility, processing-manufacture agility, partnershipformation agility, and the integration of information systems (Huang et al. 2014).

\subsection{Differentiation from other concepts}

A clear delimitation of related concepts in the following contributes to a clear understanding of $\mathrm{OA}$ and is the basis for a successful implementation in the company (Paixão and Marlow 2003). Because OA builds on previous concepts in management theory, similarities exist (Overby et al. 2006). Nevertheless, there are crucial differences that should be considered. While Overby et al. (2006) stated that OA is built on other concepts, Katayama and Bennett (1999) determined that OA and similar concepts - here leanness and adaptability — are not alternatives but, rather, 'mutually supporting concepts'. To achieve the aims of being highly responsive to changing customer demands, being cost-sensitive, and gaining high resource efficiency and corporate performance, these concepts should be implemented together (Katayama and Bennett 1999).

\subsubsection{Organizational agility and flexible organization}

Flexibility is an 'inherent property of systems which allows them to change within pre-established parameters' (Bernardes and Hanna 2009, p. 30). This capability 
exists ex ante to environmental change. Thus, flexibility, as an option for adaptation to change, is characterized by the properties of being pre-established and limited in scope and achievability. Flexibility operates as a buffer to stabilize manufacturing processes in uncertain environments. Thereby, uncertainty is absorbed and potential negative impacts reduced (Bernardes and Hanna 2009).

A notable difference is that flexibility aims to absorb and buffer environmental uncertainty, whereas OA aims to exploit environmental changes and to use them as market opportunities (Bernardes and Hanna 2009). Exploitation is facilitated by an agile organization's ability to quickly reconfigure itself (Bernardes and Hanna 2009). OA comprises several agility capabilities, one of which is flexibility (Bernardes and Hanna 2009; Yao and Carlson 2003). Hence, flexibility can be seen as an integral part of OA. Overby et al. (2006) highlighted the types of issues (according to Porter 1987) to which OA and flexibility can respond. While flexibility can cope with strategic issues, OA can respond to strategic, operational, and tactical issues. And while the speed of response plays a crucial role in the concept of OA, it does not in flexible systems (Ganguly et al. 2009). Moreover, flexibility is described as 'planned responsiveness,' while agility can cope with 'continuous, accelerated and often unpredictable changes' (Ganguly et al. 2009, p. 413). Overby et al. (2006) regarded OA as an envelopment and extension of strategic flexibility. Lin (2004) confirmed a significant relationship between manufacturing flexibility and market orientation (here regarded as one of the agility capabilities). Consequently, to enhance OA, an organization should focus on manufacturing flexibility (Lin 2004). By contrast, Giachetti (2003) considered both as two distinct system properties sharing the same objective of responding to environmental changes and uncertainty to gain a competitive advantage.

\subsubsection{Organizational agility and lean manufacturing}

OA, as well as lean manufacturing, strive for efficiency in the production process by minimizing waste. While the minimization of waste is the top goal of lean companies, agile organizations reduce waste only, without offering a quick and efficient response to unexpected changes at risk (Ganguly et al. 2009). This difference might be justified by different competitive objectives. Gunasekaran and Yusuf (2002) summarized the elimination of waste as the main goal of lean manufacturing, whereas the main goal of agile manufacturing is flexibility and customer responsiveness. Lean manufacturing strives for production efficiency by aiming for continuous improvement processes concerning resource and process usage. By contrast, OA pursues customer enrichment through the quick utilization of organizational competencies (Yusuf and Adeleye 2002). That means a more comprehensive competitive focus, including a high responsiveness of OA, in contrast to leanness (focus on low cost and high quality, respectively) (Gunasekaran and Yusuf 2002; Yusuf and Adeleye 2002). Further, the concepts can be distinguished with respect to the ability to exploit upcoming market opportunities. While this particular ability is a key characteristic of OA, it is not a focus of leanness (Paixão and Marlow 2003). Narasimhan et al. (2006) and Yusuf and Adeleye (2002) identified substantial differences in market conditions, competitive objectives, core capabilities, management 
styles, operations control, IT architecture, logistics, work organization, machine characteristics, the nature of automation, core training requirements, and overriding limitations. An exemplary representative of crucial differences is a different focus concerning machine characteristics and employees. Leanness stands for simple machines that can easily be reconfigured by 'multi-skilled operatives' (Yusuf and Adeleye 2002). OA capitalizes on knowledge workers who continually reconfigure programmable machines (see Yusuf and Adeleye 2002 for the complete list of differences).

Inman et al. (2011) outlined three fundamental views concerning the relationship between OA and lean manufacturing. First, OA and lean manufacturing are regarded as mutually exclusive concepts (Hallgren and Olhager 2009; Narasimhan et al. 2006). Ganguly et al. (2009), Paixao and Marlow (2003), and Yusuf and Adeleye (2002) suggested applying leanness in predictable environments with almost consistent demand and to implement OA in volatile environments. OA has a competitive advantage over leanness (Narasimhan et al. 2006; Yusuf and Adeleye 2002). It can outperform leanness in the following performance capabilities: conformance quality, design quality, delivery reliability, delivery speed, new product flexibility, and process flexibility (Narasimhan et al. 2006). Here, the last four provide major advantages (Narasimhan et al. 2006). Hallgren and Olhager (2009) found a higher impact of OA on the flexibility dimensions; further, the authors advised firms that employ a cost-leadership strategy to adopt leanness, while firms striving for a differentiation strategy were advised to adopt OA. The second approach is to consider $\mathrm{OA}$ and lean manufacturing as mutually supportive concepts, as Zhang and Sharifi (2000) and Yao and Carlson (2003) do. Lastly, leanness is regarded as an antecedent of OA (Gunasekaran 1999; Gunasekaran and Yusuf 2002; Paixão and Marlow 2003; Sharifi and Zhang 2001; Zhang and Sharifi 2000). Gunasekaran (1999) and Gunasekaran and Yusuf (2002) regarded agility as an advanced development of leanness with regard to flexibility and responsiveness. Zhang and Sharifi (2000) agreed with this view but also suggested that leanness is a potential enabler of OA, especially with regard to production techniques (Sharifi and Zhang 2001). Narasimhan et al. (2006) refined the relationship between the two concepts this way: 'While the pursuit of agility might presume leanness, pursuit of leanness might not presume agility' (p. 440). Yao and Carlson (2003) suggested a simultaneous pursuit of agility and leanness.

\subsubsection{Organizational agility and adaptability}

Adaptability can be seen as a feature of an organization's production system. It is defined as the 'ability to adjust or modify its cost performance according to demand' (Katayama and Bennett 1999, p. 44) and is associated with increased cost sensitivity. The reorganization of the cost structure is the main instrument used to convert fixed costs into variable costs. By contrast, OA focuses on reducing fixed costs and, thus, lowering the break-even point. Adaptable firms apply both organizational and technological solutions to improve profitability. As customer demand falls, adaptability is measured more cost-effectively compared to leanness, as the flexibility costs are higher (Katayama and Bennett 1999). 


\subsubsection{Organizational agility and responsiveness}

Responsiveness 'refers to the actions or behavior of a system using a series of capabilities to address changes triggered by stimuli' (Bernardes and Hanna 2009, p. 42). The purpose of responsiveness is to determine the appropriate time and extent of competence and capability utilization. Responsiveness depends on an external driver and aims to control the stimuli. Bernardes and Hanna (2009) described responsiveness as a further developed concept and regarded it as superior, meaning that responsiveness subsumes flexibility and agility. Contrary to this view, responsiveness is one of the four agility capabilities.

\subsubsection{Organizational agility and absorptive capacity}

Overby et al. (2006) defined absorptive capacity according to Zahra and George (2003), as 'a set of organizational routines and processes by which firms acquire, assimilate, transform, and exploit knowledge to produce a dynamic organizational capability' (p. 121). As in the OA concept, absorptive capacity emphasizes a focus on knowledge. The authors compared the acquisition and assimilation of external knowledge to the sensing part of OA, while comparing the latter dimensions of the absorptive capacity of a firm to the responding part of OA. Nonetheless, OA's focus remains on managing change instead of managing knowledge, as in the concept of absorptive capacities. Another significant difference is the continuity of the application of the concepts. While absorptive capacity performs more continuously, OA is applied solely in response to environmental changes (Overby et al. 2006).

\subsubsection{Organizational agility and market orientation}

Market orientation is, by definition, according to Kohli and Jaworski (1990), 'reflected in the organization-wide generation of market intelligence pertaining to current and future customer needs, dissemination of the intelligence across departments, and organization-wide responsiveness to it' (Overby et al. 2006, p. 121). The objective is to use resources more efficiently and effectively to satisfy customers' needs (Lin 2004). Similar to OA, market orientation relies on external information, focuses on responsiveness, and considers environmental changes (Overby et al. 2006). A major difference appears regarding its relationship to information. While comprehensive information processing plays a crucial role in an organization with the goal of "market orientation", an agile organization does not necessarily rely on information processing (Overby et al. 2006). Information processing is complex and often leads to a time loss, which can hamper OA. (Overby et al. 2006). Yet, a positive relationship could be validated between market orientation and manufacturing flexibility as an integral part of OA (Lin 2004). 


\section{Previous literature reviews}

Throughout the process of summarizing findings and categorizing the results in this SLR (Fisch and Block 2018), previous literature reviews regarding OA must not be ignored (Petticrew and Roberts 2006). Gunasekaran (1999) reviewed 60 research articles on agility in the manufacturing industry with an analytical focus on 'agile enablers' (Gunasekaran 1999, p. 88) in strategy, technology, systems, and people. The author justified a literature survey as the applied method but did not provide further information. In particular, the data collection process and the identification of relevant articles were not fully transparent and, therefore, were a methodological weak point. The result of the review was a summary of agile manufacturing key strategies and techniques. This forms the basis for the proposed framework for developing an agile manufacturing system highly focused on agility enablers. In this, strategies, technologies, systems, and people constitute the key dimensions. While the reader gets an idea of the dimensions in which agility enablers can be applied to achieve agile manufacturing, the understanding of organizational agility as a construct remains unclear. By contrast, this SLR is aimed in particular at improving the conceptual understanding of OA. Further, Gunasekaran (1999) focused exclusively on the manufacturing industry.

Yusuf et al. (1999) focused on agility in the manufacturing industry and reviewed 28 research papers without explaining the research methodology in detail. The methodological procedure for determining the relevant literature and for developing inclusion and exclusion criteria remains unclear. In addition, the authors did not explain how they came to their conclusions. The authors analyzed the content regarding agility drivers and the meaning of agility. As a result, Yusuf et al. (1999) derived a working definition of agility as follows: 'Agility is the successful exploration of competitive bases (speed, flexibility, innovation proactivity, quality and profitability) through the integration of reconfigurable resources and best practices in a knowledge-rich environment to provide customer-driven products and services in a fast changing market environment' (p. 38). Based on this, the authors identified four underlying concepts of agility and their interactions: core competence management, virtual enterprise, capability for reconfiguration, and knowledge-driven enterprise. In this connection, Yusuf et al. (1999) emphasized certain key enablers. In this literature review, too, the focus is on enabling mechanisms. The authors propose a framework for how an organization can become agile, although a conception of agility on the organizational level, which considers all the agility categories and their interactions, is still needed.

Sanchez and Nagi (2001) reviewed 73 papers on agile manufacturing systems. A systematic approach to the development of inclusion and exclusion criteria during the literature search was not comprehensively reported here. The content analysis focus was on agility enablers. A major result of this literature review was a classification scheme of existing research areas in agile manufacturing research. The authors proposed nine categories and several sub-classes in four of these categories, which enable agility in a manufacturing system. The nine categories are: product and manufacturing systems design, process planning, production planning along 
with scheduling and control, facilities design and location, material handling and storage systems, information systems, supply chain, human factors, and business practices and processes. The authors assign relevant articles to the related category, whereby most of the research was conducted in the information systems research area, followed by the supply chain research area. Based on the extensive summary of the current status of agility research in each category, Sanchez and Nagi (2001) derived ideas for further research. Again, it remains unclear as to what agility actually means conceptually in the organizational context and how the enablers work in the organization.

Potdar et al. (2017a) systematically reviewed 300 articles from research and practice with a focus on agile manufacturing. The authors critically analyzed the relevant literature regarding agility enablers, impediments, the performance outcomes of AM, and applied tools and techniques (i.e., practices to enable AM). From this, they derived critical research gaps and emphasized the research need to comprehensively analyze AM concepts in order to streamline existing frameworks with divergent views. This research gap is addressed here. By contrast, the authors assessed research efforts with respect to performance measurement, process analysis, and AM in the manufacturing industry as satisfying. Potdar et al. (2017a) did not further look at the concept of agility, nor did they look at the relationship between the various components, which is aimed at in this article.

The OA literature, until today, still seems disconnected with regard to the identified categories of OA: agility drivers, agility enablers, agility dimensions, and agility categories. The state-of-the-art shows a great need to place OA in the organizational framework and the business environment. While Gunasekaran (1999), Sanchez and Nagi (2001), and Yusuf et al. (1999) focused on factors enabling agility in the manufacturing industry, Potdar et al. (2017a) applied a more far-reaching view of the matter and additionally analyzed impeding factors and possible outputs of agility. None of the existing literature reviews fulfills the need to summarize how the various parts of agility, which have already been well-studied, work together in one concept. Therefore, this SLR addresses the need and focuses on the conceptualization of OA on an organizational level. Moreover, while the methodological approach plays a tangential role in other reviews (Gunasekaran 1999; Yusuf et al. 1999), it is a specific requirement for this review.

\section{Methodology}

\subsection{Data gathering}

A variety of publications, dissent regarding the OA concept, and high topicality in practice make an SLR reasonable. In recent years, OA research has focused on various separate research streams. Because these seem unconnected, but at the same time, do not function independently of each other, I carry out an SLR. The objective of this SLR is to restructure the complex issue of confusion respecting the functions and relationships of agility dimensions, capabilities, enablers, drivers, and the effect of OA. I theoretically and systematically conceptualize OA by compiling 
and aggregating previous key findings (Fisch and Block 2018). Further, I identify research gaps and weaknesses from a neutral perspective (Cooper 1988, 1998; Gall et al. 2006). A well-structured, transparent, and replicable methodology (Fisch and Block 2018) results in a reliable basis of knowledge (Fink 2014; Petticrew and Roberts 2006). I follow the specific process sequence according to Fink (2014) and Petticrew and Roberts (2006) to ensure completeness to the greatest extent possible and a high level of transparency (Cooper et al. 2019).

After developing research questions, I refined them through in-depth discussions with experts and practitioners before initiating the study (Cooper 1998; Fink 2014; Petticrew and Roberts 2006). All critical aspects were proved to be of great interest. In particular, targeted management was identified as a crucial challenge. Subsequently, I determined three appropriate online databases regarding the content (Academic Search Complete, Business Source Complete, and EconLit with full text) and generated a provisional result of 578 papers by applying the following search terms: 'Organi?ational agility OR agile manufacturing OR agility'. A general scope early in the literature search and a more complex, subsequent development of selection criteria aim to cover relevant papers as completely as possible. Hence, in the course of comprehensive data gathering, I developed several exclusion and inclusion criteria to identify the relevant results. The limitation was applied in regard to content and scope. Search conditions and exclusion criteria have a significant impact on the generalizability of the results and, thus, were developed systematically and carefully (Fisch and Block 2018). Therefore, I derived the following content and methodological inclusion criteria. Although the Lehigh Report (Industry Team and Facilitators 1991) cannot be classified as a scientific article, it is of great relevance to the development of OA and is considered the SLR's lead article. Thus, the time frame for the research is a date of publication between 1991 and 2018. The publication language is English. With regard to methodological criteria, the literature search included articles that involved both qualitative and quantitative research methods (Petticrew and Roberts 2006). While qualitative studies provided in-depth information about the OA concept and served as exploratory investigations, quantitative studies yielded valuable results concerning effects and quantifiable relationships (Petticrew and Roberts 2006).

I derived multiple exclusion criteria to limit the data collection to relevant results. The subjects of motor ability, telecommunication systems, and computer science are either thematically too different from the research topic (motor ability, telecommunication systems) or too specific (agility in computer science) and, thus, were excluded from the thesaurus of the databases during the literature research. Previous literature reviews and editorials were excluded because they are often subject to bias and subjectivity, especially in the case of editorials (Fink 2014; Petticrew and Roberts 2006). To ensure high quality, relevant papers were limited to publications in peer-reviewed academic journals and followed the VHB-Jourqual rating. The classification scheme $\left(A^{+}-D\right)$ evaluates the journal's scientific quality. The limitation is journals rated $A^{+}-C$ (20 top-ranked journals), thereby eliminating 350 articles. In addition, 71 duplicates were eliminated. Following, I scanned the titles and abstracts of the articles. Further exclusion criteria were developed incrementally. Overby 
et al. (2006) clearly distinguished OA from specific forms of agility. OA 'applies to sensing and responding capabilities for the entire firm' (p. 122), whereas particular forms of agility 'apply to specific processes [...] or [...] operate at different levels of analysis' (p. 122). Many of the identified articles dealt with the specific forms of supply chain agility and workforce agility. Thus, 34 articles were excluded based on content that was too narrow and which, therefore, did not correspond to the broad concept of OA on an organizational level. Although the inclusion criteria were met, 48 papers were not relevant to the research subject's thematic focus. A further specific focus of articles on particular forms of OA could be identified: IS/system development agility and strategic agility. These articles were, thus, excluded. Figure 2 summarizes and clarifies the paper selection process.

\subsection{Data analysis}

Structured data analysis constitutes the last step in the SLR process (Fink 2014). A systematic approach ensures completeness and intersubjective comprehensibility of the results. I arranged and analyzed the relevant studies in chronological order. For coding and analysis, I used a separate form and inserted the data (Cooper 1988, 1998; Gall et al. 2006). For descriptive analysis of the data, I codified the following variables: publication year, authors, title, research design, industry, investigated market (region), and research issue. In line with the urgent recommendation in methodological literature to follow a clear structure for the development of a good and clear theoretical conception, I followed concept development stages according to Podsakoff et al. (2016). If previous literature already shows different conceptual approaches, and if the goal of the research is to propose a more precise conceptual definition, as in this article, then the authors suggest a clear methodical procedure: First, a comprehensive literature review, second, the derivation of key attributes of the concept based on research results, and, finally, the aggregation of these attributes

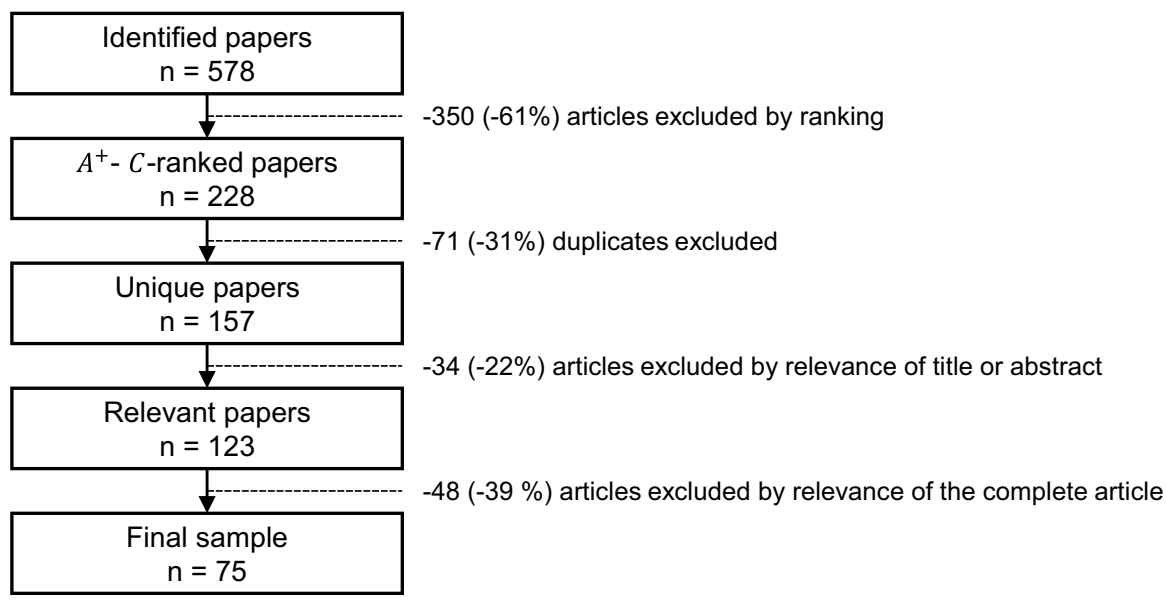

Fig. 2 Selection of relevant papers-process depiction 
in a conceptual map (Podsakoff et al. 2016). To summarize the relevant topics of the reviewed literature and provide a descriptive overview (Fisch and Block 2018), I deductively developed an alterable analysis cluster (Finfgeld-Connett 2013). The starting point and initial potential attributes of the concept (Podsakoff et al. 2016) were: the applied definition of agility in general and the original agility categories of agility drivers, agility providers, and agility capabilities (Sharifi and Zhang 1999). In addition, I analyzed the following aspects: scalability of OA (agility as a level), perspectives on OA, description of a company's business environment that requires agility, objective agility, output, and differentiation from other concepts. In the course of the analysis of the literature, I inductively and gradually added further categories or changed the names of the agility categories. Agility providers and practices are also called agility enablers. Agility attributes pertain to agility capabilities. Agility dimensions can be considered and investigated as a standalone agility category. Finfgeld-Connett (2013) emphasized the importance of alterability from a deductively developed analysis template if the goal of the SLR is 'to test, adapt, expand, and in general, improve upon the relevance and validity of existing frameworks' (p. 342), as in the case of originally defined agility categories and their relationships to each other in the holistic framework. The continuous qualitative analysis of the relevant articles enabled a determination of the necessary and sufficient attributes of the concept (Podsakoff et al. 2016). To get a first overview of the role of strategic management in the agile company, additional text passages were encoded in this regard. Here, the basis is provided by Mintzberg's (1989) classic division of management roles: informational roles, decisional roles, and interpersonal roles. The analyzed categories are directly related to the research questions. Based on this analysis, I detailed similarities and differences in previous results and summarized the development of each agility category in topical order (Fink 2014; Fisch and Block 2018). Thus, I synthesized the outcomes of previous studies (Fink 2014) and derived a contemporary conceptual map (Podsakoff et al. 2016).

\section{Results}

\subsection{Descriptive data analysis}

The first identified article was published in 1994. Research-intensive peaks can be found in 2002-2003 and 2010-2011; these are bounded by weaker research periods. Figure 3 illustrates the distribution of relevant published research papers over the years.

A total of 75 articles can be assigned to relevant journals ranked $A^{+}-C$. A percentage allocation and listing of the specific journals are provided in the online appendix. The majority of articles were published in B-ranked journals (71\%). As OA originated in the manufacturing industry, a significant number of relevant journals can be assigned to operations research and production management. In particular, in the early years of research on agility, the publication focus was on these journals. 


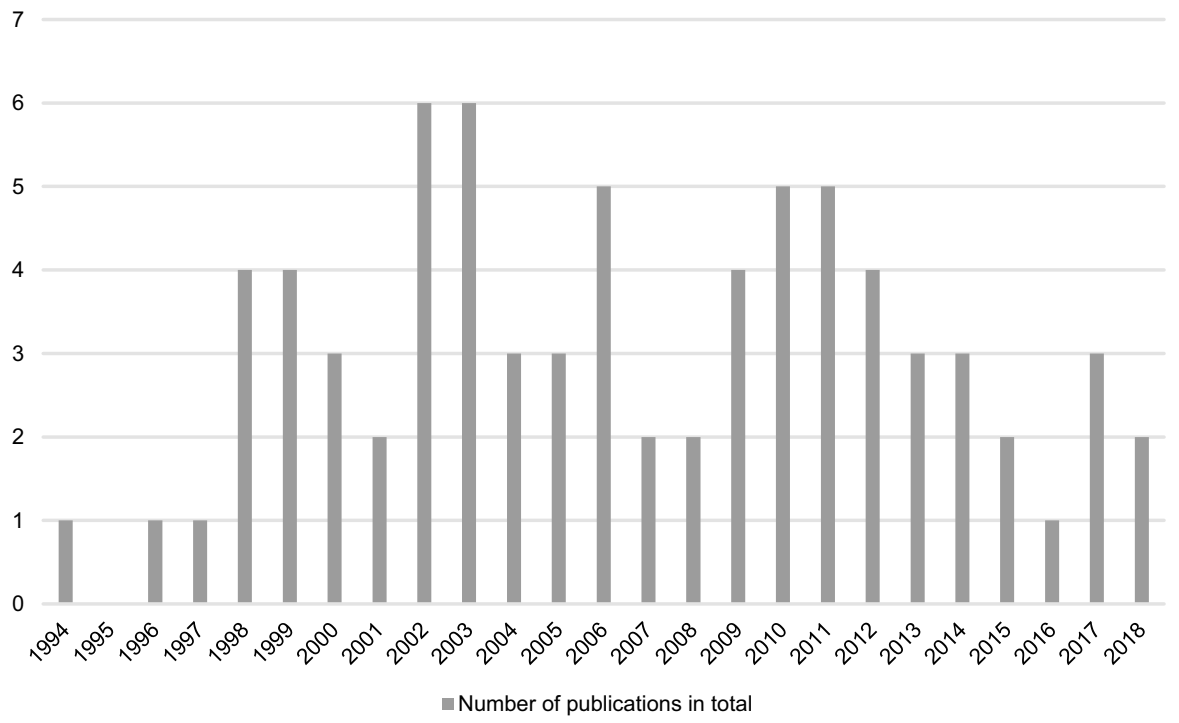

Fig. 3 Annual number of relevant published research papers

Theoretical-conceptual studies constitute the major portion (48\%) of the previous research. Quantitative research accounts for $24 \%$, whereas case studies comprise $21 \%$ (10 single case studies, 6 multiple case studies); $4 \%$ of the studies apply a mixed-method research design. Representing the minority are qualitative studies, at 3\%. The novelty of the concept in the early 1990s and the largely unresearched definitions and relationships of OA explain the presence of a large share of papers with theoretical-conceptual approaches. Most case studies used primarily qualitative methods, which are fundamentally open to the research process and research results (Mayring 2015). Thus, they are particularly appropriate for first understandings of an unknown context (Hussy et al. 2013). Qualitative methodologies generally adopt an exploratory character that is best suited to discovering the behavior of companies in a volatile environment.

Among the relevant papers, $79 \%$ investigated the manufacturing industry. The main emphasis can be justified with the origin of OA in the respective industry in 1991. However, OA is not limited to the manufacturing industry (Katayama and Bennett 1999); it applies to other business functions and service industries as well. Although alternative industries have attracted attention since 2003, the service industry remains particularly underemphasized (3\%).

OA research has focused mainly on the Asian market (22\%), with $13 \%$ focusing on India. In this regard, no specific reason, beyond the authors' geographic proximity, is identifiable. Another $11 \%$ investigated the European market, $8 \%$ of which focused on the UK. Studies in the US account for 5\%, while $61 \%$ of the reviewed articles are not region-specific. 
Although papers investigated various research questions simultaneously and, therefore, cannot be clearly assigned to a specific research topic, a tendency becomes apparent: Most articles deal with OA development and implementation (19\%). Research on agility enablers and the measurement of OA comprise $15 \%$ each. Further significant research areas are OA in general (12\%), its differentiation from other concepts $(9 \%)$, and influential factors $(9 \%)$. The remaining papers are divided into the manufacturing, scheduling, and control systems. Noticeably scant research was conducted regarding effects on firm performance (3\%) and impediments of OA (1\%).

\subsection{Conceptual map of $\mathrm{OA}$ and the role of management}

The state-of-the-art of OA research illustrates an urgent need for a conceptualization of the OA construct with a specific focus on the single categories and each category's function, interdependencies, and relationships. The developed conceptual map of $\mathrm{OA}$ is intended to improve the comprehensibility of OA and to create a better understanding of its integration into an organization. Having summarized the current state of knowledge in each agility category, I now compile the key findings and, from this, derive a holistic conceptual map of agility at an organizational level. Here, I focus in particular on relationships and interdependencies within the categories. In this context, the results of the SLR collected above are included; therefore, existing categories are expanded. Further, the category of agility dimensions is added. The categories of agility driver, agility enabler, agility capabilities, and dimensions are related to each other; functions are described and the whole is integrated as a conceptual map into the organizational context. The developed conceptual map applies a holistic view on an organizational level, while the external business environment and effects are also taken into account. Considering the agile organization as a major task of strategic management, I additionally include management responsibilities in the developed framework. With respect to the third research question, tasks and responsibilities are derived from analysis results and integrated into the conceptual map.

In the following, OA is regarded as a specific subset of dynamic capabilities, as in current literature (Hazen et al. 2017; Lu and Ramamurthy 2011; Tallon and Pinsonneault 2011; Teece et al. 2016; Vickery et al. 2010). A dynamic capability comprises routines, organizational processes, knowledge, and the entrepreneurial capability of management (Teece et al. 2016). The holistic character of dynamic capabilities fits well with OA's integrative approach. Analysis results reveal an ongoing availability of OA as an organizational capability. Thus, the organization is not continuously agile but continuously has the ability to retrieve OA capabilities.

When discussing the goal of OA, most researchers refer to competitiveness as a main objective. This must be viewed critically. Previous research investigating the effect of OA identified an increase in business performance, either direct (Hazen et al. 2017; Inman et al. 2011; Tallon and Pinsonneault 2011; Vickery et al. 2010; Yusuf and Adeleye 2002) or indirect via manufacturing strength (Vázquez-Bustelo et al. 2007) or profitability (Wang et al. 2014). Hence, increasing the agility level is 
aimed at increasing the business performance of the organization, which, in turn, can strengthen its competitiveness.

Research shows a significant dependence on environmental conditions. Turbulence in the business environment has a direct, positive influence on OA (VázquezBustelo et al. 2007) and functions as a positive moderator between OA and firm performance, resulting in a greater effect of OA on firm performance in a more volatile environment (Tallon and Pinsonneault 2011). In a business environment that does not change dynamically and unpredictably, the development of OA is economically harmful and costly rather than beneficially useful. Because OA relies heavily on environmental conditions (Teece et al. 2016), it can be seen as an 'interface between the company and the market' (Katayama and Bennett 1999, p. 44). However, OA is not always the most appropriate solution and is sometimes not realizable (Teece et al. 2016). Because its development is costly and negatively affects efficiency, organizations must identify and assess drivers and, consequently, decide on appropriate actions for staying competitive. Teece et al. (2016) emphasized the importance of clearly differentiating between uncertainty and risk. While OA is required in a highly uncertain environment, OA is unnecessary in a risky environment (Teece et al. 2016) or a stable environment (Overby et al. 2006). Narasimhan et al. (2006) and Vázquez-Bustelo et al. (2007) criticized a lack of clarity regarding specific attributes of dynamic environments. Concluding from this, $O A$ is an option to thrive and prosper in a volatile, turbulent, and uncertain competitive environment.

Concrete agility drivers can be derived from the organization's environmental conditions (Hasan et al. 2012). Agility drivers are defined as specific characteristics of the dynamic environment (Ganguly et al. 2009) that require an agile response from the organization in order to weaken the negative impact on business performance. The accumulated number of agility drivers leads to hypercompetition in the market (Chakravarty et al. 2013; Mishra et al. 2013). Moreover, environmental characteristics determine which specific agility strategies are chosen (Zhang 2011). The pivotal type of change varies over time and influences the agility need level. If the organization has adapted to the current driving force, another agility driver becomes the most powerful (Overby et al. 2006; Vinodh et al. 2012a, b). External and internal agility drivers affect agility capabilities directly and indirectly. A continuous ranking of agility drivers according to their importance impels the determination of useful agility capabilities. This means that agility drivers pressure the company to prioritize relevant agility capabilities to remain competitive (Zhang and Sharifi 2007). Management monitors the organization's environment (internal and external) and assesses changes. The situation must be assessed as uncertain (not stable, not risky). Further, management ranks the current agility drivers. These specific agility drivers lead to a hypercompetitive market. An appropriate response to hypercompetition urgently requires the realization of agility capabilities. Figure 4 zooms in on the agility drivers of the OA concept. It demonstrates the derived concept of agility drivers, its integration into the organization, and respective management tasks.

To react to the current most critically rated agility driver, the organization must develop responsive agility capabilities at certain levels by means of agility enablers. An agile response requires an intentional decision to become agile (Brown and Bessant 2003), “manufacturing choices' for agility' (Zhang and Sharifi 2007, 


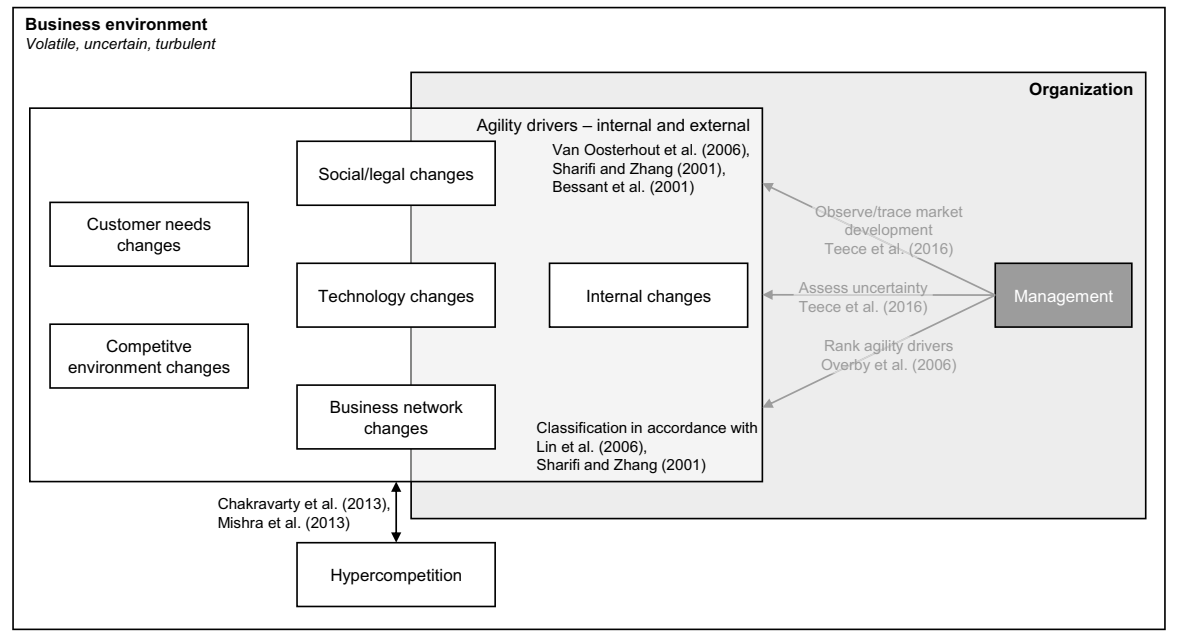

Fig. 4 Agility drivers-OA concept development

p. 352) and a 'broad vision' (Zhang and Sharifi 2000, p. 497). In this regard, Vinodh and Aravindraj (2012) stressed that an organization does not become agile by coincidence. A successful application of agility enablers - and thus, the realization of $\mathrm{OA}$ - is particularly dependent on management's conscious decision and intent to become agile (Brown and Bessant 2003; Vinodh and Aravindraj 2012; Zhang and Sharifi 2007). During this process, management must decide to consciously increase the agility level. As a response, the top team can distinguish between consciously no activities, small adjustments, and complex adaptations. Agility enablers, if strategically integrated (Brown and Bessant 2003), increase the agility level of a company and, therefore, facilitate the realization of agility capabilities. Particular agility enablers are regarded as necessary to the development of agility capabilities (Sharifi and Zhang 1999). However, a universal set of agility enablers is not generally determinable. Hence, identified agility enablers (see chapter 2.4.2) constitute a choice of methods and techniques and can be seen as a tool kit for managers, from which they must choose the most suitable combination of methods to respond effectively to changes (Zhang and Sharifi 2000). Relevant and effective agility enablers must be identified individually in consideration of the characteristics of the company and the environmental conditions (Lin 2004; Lin et al. 2006; Vinodh and Aravindraj 2012), which is a responsibility of management. Agility enablers must align with a company's strategy, processes, and existing information systems (Lin et al. 2006). Alignment between applied agility enablers determines the success of the realization of OA (Tallon and Pinsonneault 2011). If two companies have implemented agility enablers, the company with greater alignment between them performs at a higher level of OA (Tallon and Pinsonneault 2011). Moreover, interrelationships and dependencies between the applied agility enablers should be considered (Lin et al. 2006; Meade and Sarkis 1999; Tallon and Pinsonneault 2011). Both can be assigned 


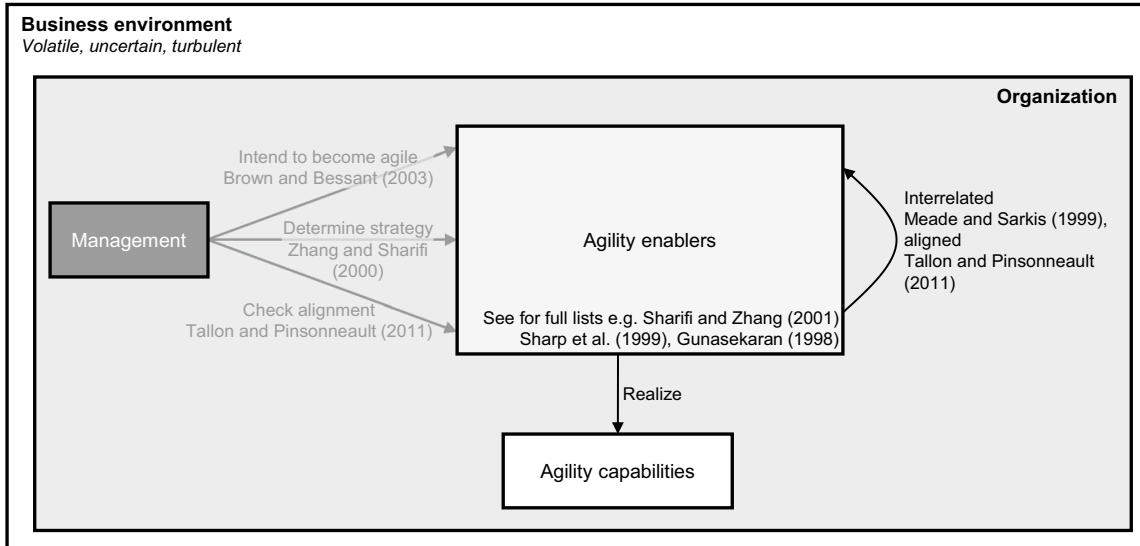

Fig. 5 Agility enablers-OA concept development

to management's responsibilities. Figure 5 describes agility enablers as an integral part of the OA concept in detail and summarizes the analysis results.

Organizations are required to develop a repertoire of capabilities to sense different types of changes and respond appropriately (Lin et al. 2006). Agility capabilities strive 'to positively respond to and take advantage of the changes' (Zhang and Sharifi 2000, p. 498). Realized agility capabilities affect business performance insofar as they diminish or even eliminate the negative effect of agility drivers on business performance (Yusuf and Adeleye 2002). Zhang and Sharifi (2000) measured the strength of correlation between each agility driver and the specific agility capabilities (sub-capabilities). Thus, the most effective capability responding to the specific driver can be determined. In the scope of this conceptualization, agility capabilities are regarded as higher-order dynamic capabilities. Organizations should develop a repertoire of capabilities to sense different types of changes and respond appropriately (Lin et al. 2006). Gunasekaran and Yusuf (2002) emphasized that the capabilities must be linked to the specific product's needs. Organizations should be able to assess the extent to which relevant agility capabilities can be or are realized and to configure the adequate approach to improve them, if required (Brown and Bessant 2003). The acquired agility capabilities are not performed continuously but, rather, are performed in uncertain situations that require a certain level of OA. Hence, an agile company is not permanently agile but has the ability and knowledge to perform agility quickly and efficiently at any time. These scalable agility capabilities must be retrievable when needed. First, the management team must determine the current, most influential agility drivers, then derive a strategy for an effective set of agility capabilities (Overby et al. 2006) and prioritize them according to their relevance (Zhang 2011). In the course of the development of agility, four generic agility capabilities are commonly referred to: responsiveness, speed, flexibility, and competency. Management must also take product, service, or customer needs into account when selecting and prioritizing agility capabilities. In addition, agility drivers should be continuously observed to determine the effectiveness of the prioritized 
agility capability. The need of the respective agility capability level can vary situationally and must be determined. Also, management must evaluate the extent to which the organization can realize the necessary capabilities. If necessary, the ability to do so must be actively improved. Then an approach must be developed regarding how the necessary capability can be enhanced or developed (using an agility enabler). Agility capabilities should be realized in each agility dimension. If each agility capability is realized in each of the agility dimensions, an overall agility capability value is subsumed in OA. If companies have sufficiently realized agility capabilities, they can quickly realize opportunities, superiorly respond to changes and uncertainty more rapidly, and take advantage of market opportunities (Giachetti et al. 2003; Sambamurthy et al. 2003; Wang et al. 2005a). Companies with high agility capabilities enhance and redefine principles of value creation through innovation (Sambamurthy et al. 2003). In summary, the overall OA consists of four (equally or diversely well-developed) agility capabilities. The value of an agility capability is the sum of the individual values of the agility capability in each agility dimension. Figure 6 demonstrates agility capabilities, their functions, and their relationships and effects within the OA concept.

The following part of the concept-agility dimensions-is the most irritating category. Although researchers pursue the same objective, i.e., the structuring of the concept of OA, here, four different approaches could be identified in the literature analysis. The classical approach regards $\mathrm{OA}$ as a process and subdivides OA into the input, mechanism, output, and control dimensions. Other researchers classify agility dimensions as different types of OA, different functionalities of OA, or

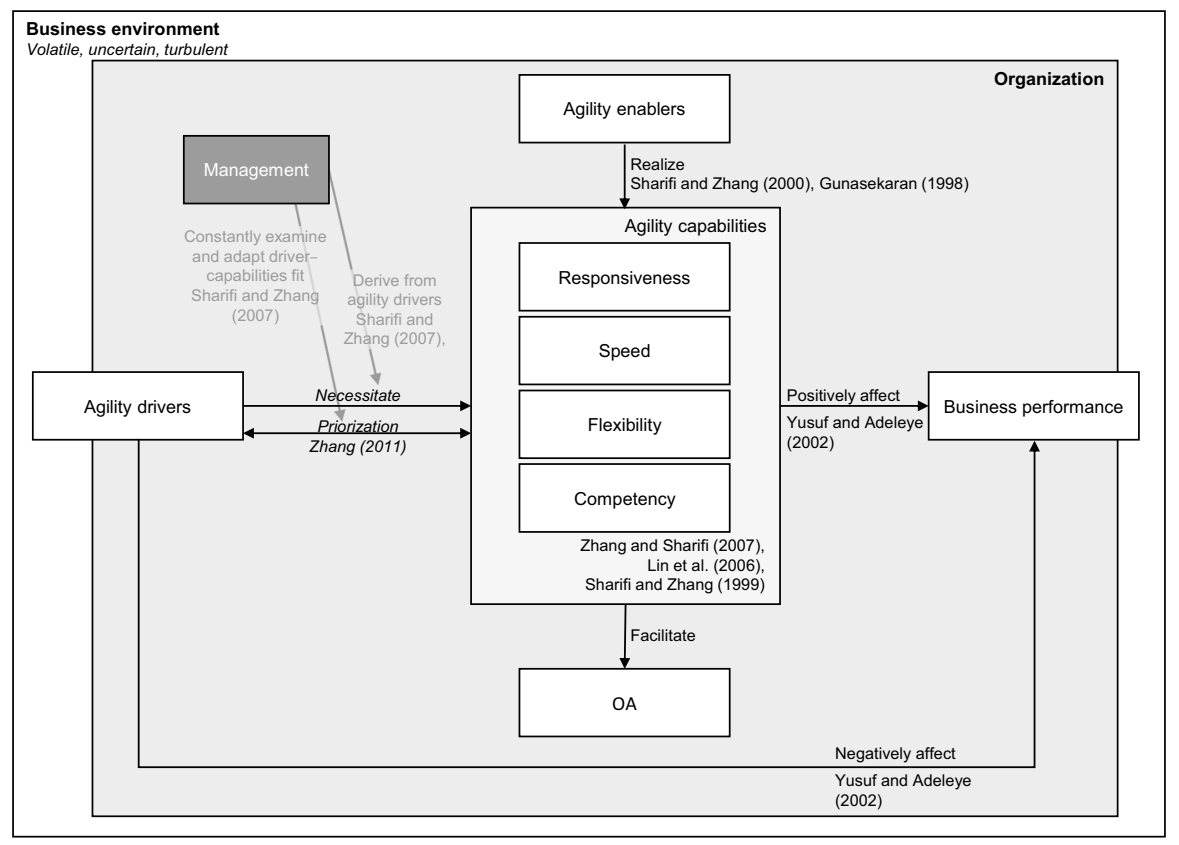

Fig. 6 Agility capabilities-OA concept development 
specific components of the agile company. In the following, due to its comprehensibility and consistency, the last is adopted and summarized. As a 'multidimensional concept' (Vázquez-Bustelo et al. 2007, p. 1305), OA must be realized and strategically integrated into diverse dimensions of the organization (Brown and Bessant 2003; Vinodh and Aravindraj 2012). Monplaisir (2002) determined that management, technology, and workforce were agility dimensions. Bessant et al. (2001) added strategy, processes, and linkages, while Lin et al. (2006) included facilities as well. These dimensions show noticeable commonalities with specific forms of OA, which were purposely excluded from the systematic literature search, as described in chapter 4. In this respect, I identified the following specific forms of OA: supply chain agility, workforce agility, strategic agility, and software development agility (IS/IT). Overby et al. (2006) clearly distinguished those forms as specific forms of OA. Furthermore, a notable number of articles deal with the practical feasibility of OA (Wang et al. 2005a, b), such as agile work cells, and can be assigned to the facilities dimension. Consequently, the structuring of OA in various components of a company is ultimately reasonable. To achieve a high level of superior OA, agility in multiple dimensions is required. The agility dimensions are now supply chain, workforce, business processes, strategy, information systems, and facilities.

To provide a comprehensive overview of the conceptualization, Fig. 7 compiles the individual elements and illustrates OA as a whole. The findings of the individual categories of OA are summarized and aggregated into a holistic concept. For this purpose, the initial basic framework in Fig. 1 was comprehensively expanded.

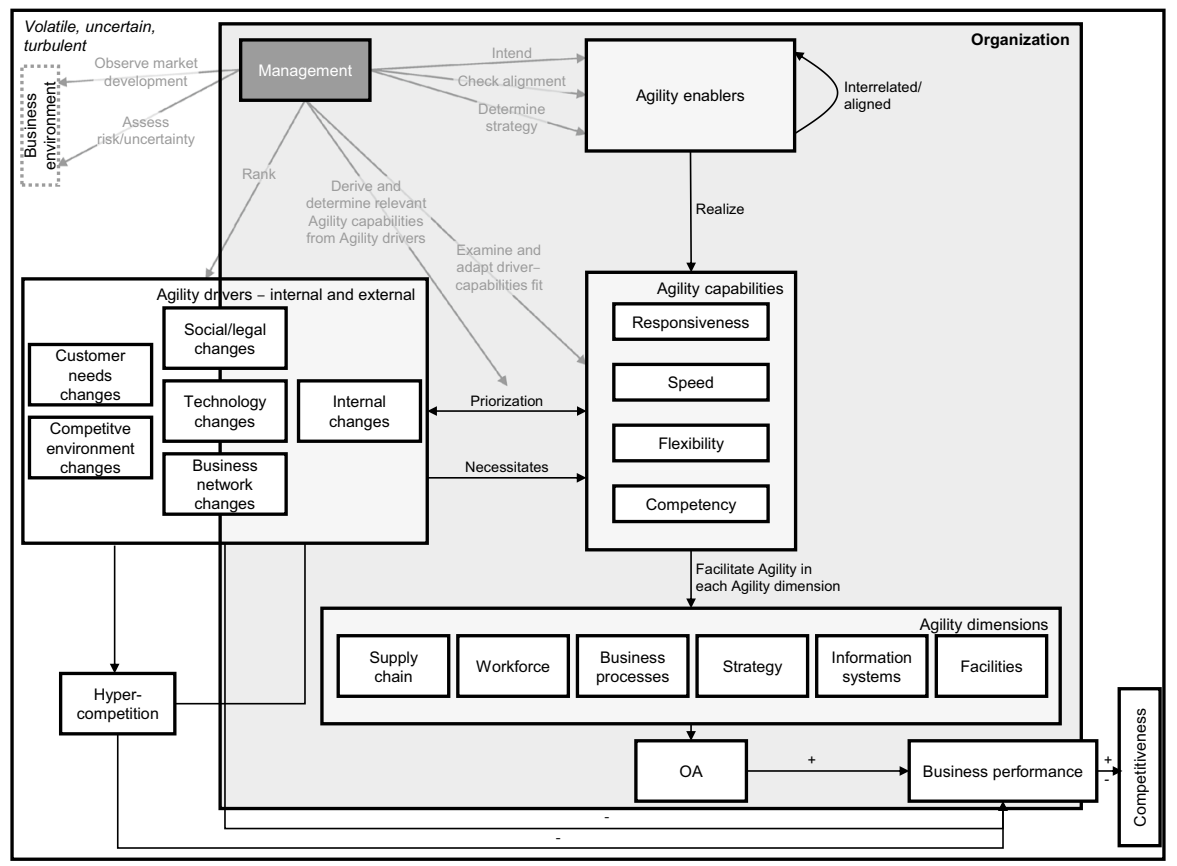

Fig. 7 Organizational agility_a conceptual map 
The integration into the organization and its environment shows how OA works in an organization and how the corporate environment is concerned. Additionally, key management tasks related to OA are summarized.

\section{Conclusion and discussion}

In current management literature, the reader comes across agility conspicuously often. There is a great interest and widespread use in the parlance. In practice, agility almost appears to be a catchphrase. Developing and implementing agility is expensive. Some business environments do not require agility; in certain cases, it would even be fatal to pursue it. However, this seems to be rarely understood in practice; agility is often seen as a panacea for remaining competitive. Academic literature demonstrates an urgent need for conceptual clarity to gain a unified understanding of agility. Initial discussions with experts prior to this SLR confirm this need. It is crucial to raise awareness of the fact that agility is not a panacea. Rather, it is an option in specific situations to remain competitive and grow. OA results from the four agility categories: agility drivers, agility enablers, agility capabilities, and agility dimensions. An inconsistent definition and use of these terms, (e.g., Paixão and Marlow 2003; Zhang and Sharifi 2007), as hitherto, must be critically assessed. This leads to a lack of consensus in the definition of OA (van Oosterhout et al. 2006). Thus, the aim of this SLR becomes all the more important-to identify, clearly define, and distinguish the existing agility categories and subsequently develop a conceptual map of OA.

In this literature review, I systematically analyzed 75 exclusively academic papers published between 1994 and 2018. As a result of the systematic literature review, I propose the following operational definition of OA: 'Organizational Agility is a learned, permanently-available dynamic capability that can be performed to a necessary degree in a quick and efficient fashion, and whenever needed in order to increase business performance in a volatile market environment.'

A systematic analysis of the literature reveals different specific OA research streams and shows a largely independent consideration of the agility categories. Existing approaches toward conceptualizing agility have, according to current knowledge, crucial conceptual gaps. Gunasekaran (1998) proposed a framework for the implementation of agility that focuses on agility enablers in manufacturing only. Sharp et al. (1999) suggested a theoretical model for agility in the manufacturing industry. Thus, the authors focused exclusively on agility enablers and objectives. Sharifi and Zhang (1999) developed a conceptual model and implementation methodology of agility comprising the categories of agility drivers, agility capabilities, and agility providers. Potential interdependencies were not considered. Zhang and Sharifi (2000) extended the framework by focusing more strongly on the agility strategy, agility drivers, and implementation process. Gunasekaran and Yusuf (2002) conceived of agility as a paradigm and developed a model of agile manufacturing strategies and techniques. Hence, the focus is on agility enablers once again. Zhang and Sharifi (2007) regarded agility as a manufacturing strategy and extended 
the existing framework (Zhang and Sharifi 2000) by proposing the dependence of agility capabilities and the organization's overall strategy. A stronger coherence between agility capabilities and agility providers becomes apparent. Vinodh et al. (2012a) developed a model for agile manufacturing. The framework considered the environment, enabling factors, and agility outcomes. Contrary to previous work, this concept referred to enabling factors as agility drivers. Overall, only a few authors have dealt with the holistic conceptualization of agility at the organizational level. To date, inconsistent definitions of the agility categories, conceptual gaps, and, above all, the lack of consideration of all agility categories at the same time led to difficulties in understanding. This SLR addresses this gap by identifying the following aspects as agility categories and finally integrating them into a coherent picture: agility drivers, agility enablers, agility capabilities, and agility dimensions. This does not address the implementation of certain agility enablers but, rather, focuses on conceptualization.

I agree with Vázquez-Bustelo et al. (2007) and see OA as a 'holistic concept,' the development of which requires the simultaneous consideration of individual components. For a clear conceptual understanding, it is fundamental to also consider the concept's origins and consequences (Podsakoff et al. 2016), in this case, the emergence of the need for OA by agility drivers, and the possible impact of an increased OA level on competitiveness. Continuously changing external and internal agility drivers can negatively impact a company's competitiveness and therefore necessitate the development of four agility capabilities. Agility capabilities comprise the responsiveness, speed, flexibility, and competency of an organization and are realized through the application of a specific set of agility enablers. Required agility enablers indicate mutual dependencies and must be aligned. An appropriate level of agility capabilities in each of the agility dimensions weakens the negative effect of agility drivers and, thereby, positively affects business performance. As a result, the firm's competitiveness can be strengthened.

Four main conclusions emerge from this SLR and are discussed in the following:

- Agility research has focused largely on specific agility enablers (Aravindraj et al. 2013; Cho et al. 1996; Gunasekaran 1998; Overby et al. 2006; Vázquez-Bustelo et al. 2007; Wang et al. 2014) and implementation methodologies (Hazen et al. 2017; Nejatian et al. 2018). To date, not enough emphasis has been placed on an overall view of the OA research strands. There is a lack of a conceptual framework that intends to explain what agility in the organization means conceptually, how the categories work, and, according to the latest findings, how the categories are interrelated. The systematic analysis of the literature reveals a shift in the research focus over time. While in earlier times agility as a whole was considered in the enterprise (Gunasekaran 1998, 1999; Sharifi and Zhang 1999; Yusuf et al. 1999; Zhang and Sharifi 2000), in the recent past, the research focus has been more on specific forms of agility, such as workforce agility (Alavi et al. 2014; Qin and Nembhard 2010; Sumukadas and Sawhney 2004; Van Oyen et al. 2001), supply chain agility (Chen 2019; Eckstein et al. 2015; Naim and Gosling 2011), information systems agility (Lyytinen and Rose 2006; Rabah et al. 2015), and strategic agility (Doz and Kosonen 2011; Fourné et al. 2014; Lewis et al. 
2014; Morton et al. 2018; Shin et al. 2015; Weber and Tarba 2014). However, the research fails to consider how the various forms of agility in the enterprise then work together to increase the overall agility level of the organization. The focus on the enhancement of only one meta-form of agility, e.g., strategic agility, is not sufficient and should be considered together with the other agility dimensions. The research interest of this paper builds on this. To successfully implement OA, it is critical to fully understand the concept and to clearly differentiate the various agility categories. The developed theoretical framework clearly separates individual components and derives interrelationships and mechanisms. In this, agility is not viewed as a yes-no decision but, rather, as a continuum, integrated into a holistic concept, connected to the organizational context and business environment, and is considered independent of the industry.

- Agility dimensions are constantly present in the literature (Bessant et al. 2001; Coronado et al. 2002, 2004; Meade and Sarkis 1999; Monplaisir 2002; Paixão and Marlow 2003; van Oosterhout et al. 2006; Vázquez-Bustelo et al. 2007; Vinodh 2010; Zandi and Tavana 2011) and yet represent a critical definition problem. An in-depth literature analysis indicates the function of agility dimensions in structuring OA and mapping various subcategories in which agility must be present to achieve agility at the organizational level. The conceptual map suggests considering the specific OA research streams (subcategories of OA) as agility dimensions. After all, these are interdependent and future research must integrate the research results regarding the specific agility dimensions. Due to interdependencies, I do not recommend an isolated view and a focus on only one agility dimension. The proposed conceptual map can serve as a basic framework for studying interactions and integrating the results.

- An agile organization is both internally and externally oriented. Internally, the organization shows a high level of vigilance with regard to the coordination of the various agility categories. Potential interdependencies and their alignment must also be considered. Externally, the organization focuses on environmental changes and the impact on the competitive market. This means a constant high level of attention, which leads to the next point.

- OA is a comprehensive organizational concept that is part of strategic management at the time of realization. In summarizing management's tasks, a major role of management in the construct of OA becomes apparent. In terms of management activities, in summary, the monitoring and decision-making functions (Mintzberg 1973, 1989) play a key role in the implementation of OA in the company. As a monitor, management assumes an information role (Mintzberg 1973, 1989), continuously gathering information from the corporate environment and, thus, determining agility drivers. Management observes and traces market development and assesses and distinguishes between risk and uncertainty. Management also determines a ranking of the agility drivers regarding their current influence on the organization. Furthermore, management in the agile company realizes decision-oriented roles. As an entrepreneur, the manager proactively responds to identified trends or, as a disturbance handler, involuntarily responds to developments that cannot be influenced by deliberately initiating the increase of the agility level and selecting and implementing the appropriate set of agil- 
ity enablers (Mintzberg 1973, 1989). Further, the management team must have the explicit intent to become agile, decide on a specific set of agility enablers, and, consequently, check the alignment between the individual agility enablers. During the realization of the agility enablers, actions are supposed to be continuously integrated into the company's activity system, while interactions with each other and with the environment are to be monitored. In the case of discrepancies, a decision is made immediately and the set of agility enablers is adjusted. In addition, management continually monitors the organization's ability to adequately realize the necessary agility capabilities. If skills are insufficient, the decision about improvement measures is made immediately. Close cooperation in the monitoring of activities and decision-critical activities described above shows that, in practice, the roles of management according to Mintzberg (1973, 1989) cannot be considered and function separately from one another. In addition to information roles and decision-oriented roles, Mintzberg (1973, 1989) introduced interpersonal roles. I suspect that interpersonal roles are critical to success in the actual implementation process of agility capabilities in the company, which can be seen as a major change in the company. When one is looking at management as a function, it should be noted that three key functions must be fulfilled in the company regarding agility: planning the realization of agility capabilities, organizing and coordinating the chosen agility enablers, and controlling the target-performance situation (Steinmann et al. 2013). These are part of the schematic process of strategic management in an agile company. In the beginning, both the opportunities and risks in the corporate environment are analyzed and changes are recognized, as are the strengths and weaknesses of the company. Management assesses the extent to which the organization can already realize the necessary agility capabilities. Consequently, various strategic options are derived, i.e., possible sets of agility enablers are compiled, from which a particular option is strategically selected and implemented by strategic programs. During the entire strategic management process, the strategic control and a target-performance comparison take place. This means that, throughout the process, agility drivers are observed and their impact assessed and ranked. Further, the interaction of the agility enablers with each other and their effectiveness on agility capabilities is evaluated.

To the best of my knowledge, this paper is the first to systematically review individual agility categories, respective functions, and interrelationships. Summarizing, classifying, and critically analyzing existing research results significantly contributes to OA research and provides a basis for improvements, especially in the measurement and implementation of OA. In this regard, Block and Kuckertz (2018) acknowledged the great importance of SLRs. By defining OA as a specific dynamic capability within the suggested conceptual framework, this article also contributes to the enrichment of the dynamic capabilities discourse. The article connects mainly to current discussions about the behavior of organizations in complex, volatile, and uncertain environments. The OA concept offers a promising opportunity to explain how to remain competitive in this particular business environment. Because the 
results of this SLR indicate the realization of this concept as a major task of strategic management, this paper also contributes to strategic management research.

Equally important are valuable contributions to management in practice. This research paper presents a concept of OA based on previous findings, which have been aggregated into an overall picture to help organizations that strive for agility. Managers can take advantage of the results by applying the depicted concept and making use of new insights. With respect to preparatory expert interviews, prior to the SLR, considerable uncertainty regarding the meaning of OA, especially the function of agility enablers and the differentiation of agility capabilities, became apparent. A clear distinction of these agility categories and the description of agility enablers as a toolkit may improve OA performance in practice and provide guidance for managers. The results of the SLR and the developed conceptual map show when OA is to be applied, how agility is to be understood as a capability of an organization, which areas of the company are integrated, and how the organizational dynamic capability OA is to be distinguished from agile methods. For instance, Scrum is an exemplary agile method that works well in a large number of organizations (Scrum Alliance 2018) and demonstrates an appropriate solution to realize agility capabilities. Nevertheless, in accordance with Zhang and Sharifi (2000), this is one example from a wide-ranging method box of agility enablers, from which each organization must choose and combine enablers specifically according to its characteristics and situation. First, in 2019, I found an article from a renowned consultancy, which is aimed at practicing managers and clearly emphasizes that an organization's focus must be on the development of basic agility capabilities and that the overall picture of an agile organization should be kept in mind (Mahadevan et al. 2019). This understanding can be increased by a deeper knowledge of the inter-organizational connections of the agility categories. The developed framework of OA can serve as a point of reference for orientation in practice and further discussion with experts.

\section{Limitations and future research}

This SLR summarizes, categorizes, and challenges existing OA research results and, therefore, can serve as an essential prerequisite for further research projects (Block and Kuckertz 2018; Fisch and Block 2018). Although I followed a structured research systematic, this study has notable limitations. Due to the significant amount of research in this area, specific forms of OA were excluded. I focused solely on agility at the organizational level. The search process was conducted automatedly with clear exclusion criteria in an online search engine. Potentially relevant research outcomes, such as conference contributions, working papers, or books, were not part of the review. Though classics like the twenty-first Century Manufacturing Enterprise Strategy Report (Industry Team and Facilitators 1991), Goldman et al. (1995), and Kidd (1994) were part of the extensive preparatory work, they are not part of the SLR. Moreover, I followed the VHB JOURQUAL 3 ranking and focused on $\mathrm{A}+$ - to C-ranked journals, which means the categorical exclusion of further journals. Additionally, there is a risk that by applying the search strings in the automated 
search in the three databases, not all relevant articles could be captured by scanning the title and abstract (Hatzijordanou et al. 2019).

The results of the analysis opened up various OA research opportunities to enhance and refine scientific insights and, subsequently, improve OA understanding and implementation. The current state of research and the results of this article suggest empirically testing the developed conceptual model. In particular, further research on agility dimensions is needed. This is justified by the fact that, to date, the extensive research works in the individual OA research streams (here conceptualized as agility dimensions) have been largely detached and considered independent of each other. At this point, an intensive investigation of the interdependence of the agility dimensions and their effects on higher-level OA is necessary. By further neglecting the assumed dependence on each other, I suspect the presence of the risk of overlooking correlations, interfering effects, or even synergies of two agility dimensions. These possible effects would have a significant impact on OA. The results of the SLR suggest that management plays a key role in agile organizations. As the results of the SLR provide a first insight into the area of the responsibility of management in the agile environment, further interesting research questions arise. In addition to management, Lewis et al. (2014) case study has provided insight into paradoxical leadership in the specific context of strategic agility. Key findings could form the basis for further exploratory, qualitative research on agile management. Meanwhile, the ongoing discussion in management research is about management's changing role and a declining area of responsibility, especially in middle management. Decision-making power remains a key responsibility in an agile setting. This could be a starting point for further discussion and closer investigation. The influence of different management styles on the implementation success of OA could be another promising research focus. Moreover, the results of the SLR suggest a phased and situation-dependent realization of the learned agility capabilities. I assume that the capabilities and processes that are retrieved here have been learned beforehand. A comprehensive understanding of the process and a clear distinction between the learning and realization parts requires extensive investigation. An exploratory, in-depth, longitudinal case study could offer exciting insights into the exact course of this process. Additionally, case study research could be aimed at a bestpractice scenario for the learning of agility capabilities. In sum, researchers have largely investigated how agility capabilities can be realized by certain agility enablers. It is also necessary to explain specific use cases of OA in companies. How specifically do agility capabilities affect certain disruptive factors (agility drivers)? How can agility capabilities mitigate the negative impact of agility drivers? Exploratory case-study research, which has been neglected so far, could help to answer these questions. In recent years, research design has mostly been theoretical-conceptual. Further qualitative research has the potential to uncover valuable in-depth insights and interesting relationships. The realization of agility depends on a variety of factors. While the enabling factors have already been extensively investigated, only a few investigations (Hasan et al. 2007; Potdar et al. 2017b) have examined potential obstacles to OA. However, I recommend addressing these issues properly to fully realize $\mathrm{OA}$ and to subsequently derive measures 
to counteract potential barriers in a targeted and proactive manner. Particularly interesting might be a focus on the corporate size. Especially for small and medium-sized enterprises, OA plays a crucial role (Bessant et al. 2001). However, encrusted structures and limited resources often make it difficult for small and medium-sized enterprises to change. Supposedly, start-ups develop OA more easily (Teece et al. 2016). Thus, a comparative case study between different-sized enterprise types is a promising approach toward investigating this hypothesis. Further OA research is required to focus on industries other than manufacturing. A comparative case study in the service and production industries would likely reveal critical differences. An examination of the influence of different regions could produce exciting insights, as the focus until now has been on Asia (India). I hope that this paper will encourage researchers to further OA research and inspire potential research directions and that the developed conceptual map serves as a basis for this.

Acknowledgements Open Access funding provided by Projekt DEAL. The research was funded by the European Social Fund and co-financed by tax funds based on the budget decided by the members of the Saxon State Parliament.

Open Access This article is licensed under a Creative Commons Attribution 4.0 International License, which permits use, sharing, adaptation, distribution and reproduction in any medium or format, as long as you give appropriate credit to the original author(s) and the source, provide a link to the Creative Commons licence, and indicate if changes were made. The images or other third party material in this article are included in the article's Creative Commons licence, unless indicated otherwise in a credit line to the material. If material is not included in the article's Creative Commons licence and your intended use is not permitted by statutory regulation or exceeds the permitted use, you will need to obtain permission directly from the copyright holder. To view a copy of this licence, visit http://creativecommons.org/licen ses/by/4.0/.

\section{References}

Ahlbäck K, Fahrbach C, Murarka M, Salo O (2017) How to create an agile organization. McKinsey \& Company Organization. https://www.mckinsey.com/business-functions/organization/our-insights/ how-to-create-an-agile-organization. Accessed 2 Sept 2019

Alavi S, Wahab DA, Muhamad N, Shirani BA (2014) Organic structure and organisational learning as the main antecedents of workforce agility. Int J Prod Res 52(21):6273-6295. https://doi. org/10.1080/00207543.2014.919420

Scrum Alliance (2018) State of Scrum 2017-2018. Scrum Alliance. https://www.scrumalliance.org/learn -about-scrum/state-of-scrum. Accessed 2 Sept 2019

Aravindraj S, Sudheer A, Vinodh S, Anand G (2013) A mathematical model to evaluate the role of agility enablers and criteria in a manufacturing environment. Int J Prod Res 51(19):5971-5984. https:// doi.org/10.1080/00207543.2013.825381

Bernardes SE, Hanna MD (2009) A theoretical review of flexibility, agility and responsiveness in the operations management literature: toward a conceptual definition of customer responsiveness. Int J Oper Prod Man 29(1):30-53. https://doi.org/10.1108/01443570910925352

Bessant J, Francis D, Meredith S, Kaplinsky R, Brown S (2001) Developing manufacturing agility in SMEs. Int J Technol Manage 22(1-3):28-54. https://doi.org/10.1504/ijmtm.2000.001374

Block J, Kuckertz A (2018) Seven principles of effective replication studies: strengthening the evidence base of management research. Manag Rev Q 68(4):355-359. https://doi.org/10.1007/s1130 $1-018-0149-3$ 
Bottani E (2009) A fuzzy QFD approach to achieve agility. Int J Prod Econ 119(2):380-391. https://doi. org/10.1016/j.ijpe.2009.02.013

Brown JL, Agnew NM (1982) Corporate agility. Bus Horizons 25(2):29-33. https://doi.org/10.1016/00076813(82)90101-X

Brown S, Bessant J (2003) The manufacturing strategy-capabilities links in mass customisation and agile manufacturing - an exploratory study. Int J Oper Prod Man 23(7):707-730. https://doi. org/10.1108/01443570310481522

Business Agility Institute (2019) The business agility report. Business Agility Institute. https://businessag ility.institute/learn/2019-business-agility-report-raising-the-bar/. Accessed 2 September 2019.

Calvo R, Domingo R, Sebastián MA (2008) Systemic criterion of sustainability in agile manufacturing. Int J Prod Res 46(12):3345-3358. https://doi.org/10.1080/00207540601096957

Cao Q, Dowlatshahi S (2005) The impact of alignment between virtual enterprise and information technology on business performance in an agile manufacturing environment. J Oper Manag 23(5):531550. https://doi.org/10.1016/j.jom.2004.10.010

Chakravarty A, Grewal R, Sambamurthy V (2013) Information technology competencies, organizational agility, and firm performance: enabling and facilitating roles. Inform Syst Res 24(4):976-997. https ://doi.org/10.1287/isre.2013.0500

Chen CJ (2019) Developing a model for supply chain agility and innovativeness to enhance firms' competitive advantage. Manag Decis 57(7):1511-1534. https://doi.org/10.1108/md-12-2017-1236

Cheng K, Pan PY, Harrison DK (2000) The Internet as a tool with application to agile manufacturing: a web-based engineering approach and its implementation issues. Int J Prod Res 38(12):2743-2759. https://doi.org/10.1080/002075400411466

Cho H, Jung M, Kim M (1996) Enabling technologies of agile manufacturing and its related activities in Korea. Comput Ind Eng 30(3):323-334. https://doi.org/10.1016/0360-8352(96)00001-0

Cooper HM (1988) Organizing knowledge syntheses: a taxonomy of literature reviews. Knowl Soc 1(1):104-126. https://doi.org/10.1007/bf03177550

Cooper HM (1998) Synthesizing research: a guide for literature reviews, 3rd edn. Sage Publications, Thousand Oaks

Cooper HM, Hedges LV, Valentine JC (2019) The handbook of research synthesis and meta-analysis, 3rd edn. Russell Sage Foundation, New York

Coronado Mondragon AE, Sarhadi M, Millar C (2002) Defining a framework for information systems requirements for agile manufacturing. Int J Prod Econ 75(1-2):57-68. https://doi.org/10.1016/ s0925-5273(01)00181-5

Coronado Mondragon AE, Lyons AC, Kehoe DF (2004) Assessing the value of information systems in supporting agility in high-tech manufacturing enterprises. Int J Oper Prod Man 24(12):1219-1246. https://doi.org/10.1108/01443570410569029

De Smet A, Aghina W (2015) The keys to organizational agility. McKinsey \& Company. https://www. mckinsey.com/business-functions/organization/our-insights/the-keys-to-organizational-agility. Accessed 2 Sept 2019

Doz Y, Kosonen M (2011) Nokia and Strategic agility: a postscript. Calif Manag Rev 53(4):154-156. https://doi.org/10.1525/cmr.2011.53.4.154

Ebrahim S, Krishnakanthan K, Thaker, S (2018) Agile compendium. McKinsey \& Company. https:// www.mckinsey.com/business-functions/organization/our-insights/harnessing-agile-compendium ?cid=eml-web. Accessed 2 Sept 2019

Eckstein D, Goellner M, Blome C, Henke M (2015) The performance impact of supply chain agility and supply chain adaptability: the moderating effect of product complexity. Int J Prod Res 53(10):3028-3046. https://doi.org/10.1080/00207543.2014.970707

Eisenhardt KM, Martin JA (2000) Dynamic capabilities: what are they? Strateg Manag J 21(1011):1105-1121. https://doi.org/10.1002/1097-0266(200010/11)21:10/11\%3c1105:aid-smj13 3\%3e3.0.co;2-e

Eshlaghy AT, Mashayekhi AN, Rajabzadeh A, Razavian MM (2010) Applying path analysis method in defining effective factors in organisation agility. Int J Prod Res 48(6):1765-1786. https://doi. org/10.1080/00207540802566410

Feng SC, Zhang C (1998) A modular architecture for rapid development of CAPP systems for agile manufacturing. IIE Trans 30(10):893-903. https://doi.org/10.1080/07408179808966543

Ferrier WJ, Smith KG, Grimm CM (1999) The role of competitive action in market share erosion and industry dethronement: a study of industry leaders and challengers. Acad Manag J 42(4):372-388. https://doi.org/10.2307/257009 
Finfgeld-Connett D (2013) Use of content analysis to conduct knowledge-building and theory-generating qualitative systematic reviews. Qual Res 14(3):341-352. https://doi.org/10.1177/1468794113 481790

Fink A (2014) Conducting research literature reviews: from the internet to paper. SAGE Publications Inc, Los Angeles

Fisch C, Block J (2018) Six tips for your (systematic) literature review in business and management research. Manag Rev Q 68(2):103-106. https://doi.org/10.1007/s11301-018-0142-X

Fourné SPL, Jansen JJP, Mom TJM (2014) Strategic agility in MNEs: managing tensions to capture opportunities across emerging and established markets. Calif Manag Rev 56(3):13-38. https://doi. org/10.1525/cmr.2014.56.3.13

Gall MD, Gall JP, Borg WR (2006) Educational research: an introduction, 8th edn. Pearson Education Inc, Boston

Ganguly A, Nilchiani R, Farr JV (2009) Evaluating agility in corporate enterprises. Int J Prod Econ 118(2):410-423. https://doi.org/10.1016/j.ijpe.2008.12.009

Giachetti RE, Martinez LD, Sáenz OA, Chen CS (2003) Analysis of the structural measures of flexibility and agility using a measurement theoretical framework. Int J Prod Econ 86(1):47-62. https://doi. org/10.1016/s0925-5273(03)00004-5

Glenn M (2009) Organizational agility: how business can survive and thrive in turbulent times. Economist Intelligence Unit Limited, London

Goldman SL, Nagel RN, Preiss K (1995) Agile competitors and virtual organizations - strategies for enriching the customer. Van Nostrand Reinhold, London

Guisinger A, Ghorashi B (2004) Agile manufacturing practices in the specialty chemical industry: an overview of the trends and results of a specific case study. Int J Oper Prod Man 24(6):625-635. https://doi.org/10.1108/01443570410538140

Gunasekaran A (1999) Agile manufacturing: a framework for research and development. Int J Prod Econ 62(1-2):87-105. https://doi.org/10.1016/s0925-5273(98)00222-9

Gunasekaran A (1998) Agile manufacturing: enablers and an implementation framework. Int J Prod Res 36(5):1223-1247. https://doi.org/10.1080/002075498193291

Gunasekaran A, Yusuf YY (2002) Agile manufacturing: a taxonomy of strategic and technological imperatives. Int J Prod Res 40(6):1357-1385. https://doi.org/10.1080/00207540110118370

Gunasekaran A, Yusuf YY, Adeleye EO, Papadopoulos T (2018) Agile manufacturing practices: the role of big data and business analytics with multiple case studies. Int J Prod Res 56(1-2):385397. https://doi.org/10.1080/00207543.2017.1395488

Hallgren M, Olhager J (2009) Lean and agile manufacturing: external and internal drivers and performance outcomes. Int J Oper Prod Man 29(10):976-999. https://doi.org/10.1108/0144357091 0993456

Hasan MA, Shankar R, Sarkis J (2007) A study of barriers to agile manufacturing. Int J Agile Syst Manag 2(1):1-22. https://doi.org/10.1504/ijasm.2007.015679

Hasan MA, Sarkis J, Shankar R (2012) Agility and production flow layouts: an analytical decision analysis. Comput Ind Eng 62(4):898-907. https://doi.org/10.1016/j.cie.2011.12.011

Hatzijordanou N, Bohn N, Terzidis O (2019) A systematic literature review on competitor analysis: status quo and start-up specifics. Manag Rev Q 69(4):415-458. https://doi.org/10.1007/s1130 1-019-00158-5

Hazen BT, Bradley RV, Bell JE, In J, Byrd TA (2017) Enterprise architecture: a competence-based approach to achieving agility and firm performance. Int J Prod Econ 193:566-577. https://doi. org/10.1016/j.ijpe.2017.08.022

Huang PY, Pan SL, Ouyang TH (2014) Developing information processing capability for operational agility: implications from a Chinese manufacturer. Eur J Inform Syst 23(4):462-480. https://doi. org/10.1057/ejis.2014.4

Hult GTM, Ketchen DJ Jr, Slater SF (2005) Market orientation and performance: an integration of disparate approaches. Strateg Manag J 26(12):1173-1181. https://doi.org/10.1002/smj.494

Hussy W, Schreier M, Echterhoff G (2013) Forschungsmethoden in Psychologie und Sozialwissenschaft, 2nd edn. Springer, Berlin

Industry Team and Facilitators (1991) 21st Century manufacturing enterprise strategy. an industry-led view (Volume 1+2). Bethlehem, PA: Iacocca Institute, Lehigh University. https://apps.dtic.mil/ dtic/tr/fulltext/u2/a257032.pdf. Accessed 27 Sept 2017 
Inman RA, Sale RS, Green KW, Whitten D (2011) Agile manufacturing: relation to JIT, operational performance and firm performance. J Oper Manag 29(4):343-355. https://doi.org/10.1016/j. jom.2010.06.001

Iyer S, Nagi R (1997) Automated retrieval and ranking of similar parts in agile manufacturing. IIE Trans 29(10):859-876. https://doi.org/10.1080/07408179708966407

Jarrar Y, Zairi M (2000) Best practice transfer for future competitiveness: a study of best practices. Total Qual Manag 11(4-6):734-740. https://doi.org/10.1080/09544120050008147

Katayama H, Bennett D (1999) Agility, adaptability and leanness: a comparison of concepts and a study of practice. Int J Prod Econ 60-61:43-51. https://doi.org/10.1016/s0925-5273(98)00129 $-7$

Kidd PT (1994) Agile manufacturing: forging new frontiers. Addison-Wesley Longman Publishing Co. Inc., Boston

Klein HJ, Molloy J, Cooper J (2009) Conceptual foundations: construct definitions and theoretical representations of workplace commitments. In: Klein HJ, Becker TE, Meyer JP (eds) Commitment in organizations: accumulated wisdom and new directions. Routledge, New York, pp 3-36

Kohli AK, Jaworski BJ (1990) Market orientation: the construct, research, propositions, and managerial implications. J Mark 54(2):1-18. https://doi.org/10.2307/1251866

Lee OKD, Sambamurthy V, Lim KH, Wei KK (2003) The moderating effects of environmental dynamism on the links between IT management and agility: a moderated mediation analysis. Working paper, University of Massachusetts, Boston.

Lee OKD, Sambamurthy V, Lim KH, Wei KK (2015) How does it ambidexterity impact organizational agility? Inform Syst Res 26(2):398-417. https://doi.org/10.1287/isre.2015.0577

Lewis MW, Andiopoulos C, Smith WK (2014) Paradoxical leadership to enable strategic agility. Calif Manag Rev 56(3):58-77. https://doi.org/10.1525/cmr.2014.56.3.58

Lin BW (2004) Original equipment manufacturers (OEM) manufacturing strategy for network innovation agility: the case of Taiwanese manufacturing networks. Int J Prod Res 42(5):943-957. https ://doi.org/10.1080/00207540310001622449

Lin CT, Chiu H, Tseng YH (2006) Agility evaluation using fuzzy logic. Int J Prod Econ 101(2):353368. https://doi.org/10.1016/j.ijpe.2005.01.011

Lumpkin GT, Dess GG (1996) Clarifying the entrepreneurial orientation construct and linking it to performance. Acad Manag Rev 21(1):135-172. https://doi.org/10.5465/amr.1996.9602161568

Lu Y, Ramamurthy K (2011) Understanding the link between information technology capability and organizational agility: an empirical examination. MIS Quart 35(4):931-954. https://doi. org/10.2307/41409967

Lyytinen K, Rose GM (2006) Information system development agility as organizational learning. Eur J Inf Syst 15:183-199. https://doi.org/10.1057/palgrave.ejis.3000604

Mahadevan D, Paquette C, Rashid N, Ustinov E (2019) Building agile capabilities: The fuel to power your agile 'body'. McKinsey \& Company Organization Practice. https://www.mckinsey.com/busin ess-functions/organization/our-insights/building-agile-capabilities-the-fuel-to-power-your-agile -body?cid=other-eml-alt-mip-mck\&hlkid=133ff61560764ccdb5047068e34c2577\&hctky=10277 963\&hdpid=24dcbd4a-03b2-4ae6-8e6a-ea7cb89b175e. Accessed 2 Sept 2019

Mayring P (2015) Qualitative Inhaltsanalyse: Grundlagen und Techniken. 12th ed. Beltz

McKinsey (2019) Five Fifty: Agility at the top. [online] McKinsey Quarterly. Available at: https://www. mckinsey.com/featured-insights/leadership/five-fifty-agility-at-the-top. Accessed 3 July 2019

Meade LM, Sarkis J (1999) Analyzing organizational project alternatives for agile manufacturing processes: an analytical network approach. Int J Prod Res 37(2):241-261. https://doi. org/10.1080/002075499191751

Meinhardt R, Junge S, Weiss M (2018) The organizational environment with its measures, antecedents, and consequences: a review and research agenda. Manag Rev Q 68:195-235. https://doi. org/10.1007/s11301-018-0137-7

Miller D, Friesen PH (1983) Strategy-making and environment: the third link. Strateg Manag J 4(3):221235. https://doi.org/10.1002/smj.4250040304

Mintzberg H (1973) The nature of managerial work. Longman, New York

Mintzberg H (1989) Mintzberg on Management: Inside Our Strange World of Organizations. Free Press, Mumbai

Mishra S, Datta S, Mahapatra SS (2013) Grey-based and fuzzy TOPSIS decision-making approach for agility evaluation of mass customization systems. Benchmark Int J 20(4):440-462 
Mishra S, Mahapatra SS, Datta S (2014) Agility evaluation in fuzzy context: influence of decision-makers' risk bearing attitude. Benchmark Int J 21(6):1084-1119

Monplaisir L (2002) Enhancing CSCW with advanced decision making tools for an agile manufacturing system design application. Group Decis Negot 11:45-63. https://doi.org/10.1023/A:1014538003 326

Morton J, Stacey P, Mohn M (2018) Building and maintaining strategic agility: an agenda and framework for executive IT leaders. Calif Manage Rev 61(1):94-113. https://doi.org/10.1177/0008125618 790245

Naim MM, Gosling J (2011) On leanness, agility and leagile supply chains. Int J of Prod Econ 131(1):342-354. https://doi.org/10.1016/j.ijpe.2010.04.045

Narasimhan R, Swink M, Kim SW (2006) Disentangling leanness and agility: an empirical investigation. J Oper Manag 24(5):440-457. https://doi.org/10.1016/j.jom.2005.11.011

Nejatian M, Zarei MH, Nejati M, Zanjirchi SM (2018) A hybrid approach to achieve organizational agility: an empirical study of a food company. Benchmark Int J 25(1):201-234

Overby E, Bharadwaj A, Sambamurthy V (2006) Enterprise agility and the enabling role of information technology. Eur J Inform Syst 15:120-131. https://doi.org/10.1057/palgrave.ejis.3000600

Paixão AC, Marlow BP (2003) Fourth generation ports—a question of agility? Int J Phys Distr Log 33(4):355-376. https://doi.org/10.1108/09600030310478810

Petticrew M, Roberts H (2006) Systematic reviews in the social sciences: a practical guide. Blackwell, Amsterdam

Podsakoff PM, MacKenzie SB, Podsakoff NP (2016) Recommendations for creating better concept definitions in the organizational, behavioral, and social sciences. Org Res Methods 19(2):159-203. https://doi.org/10.1177/1094428115624965

Porter ME (1987) From competitive advantage to corporate strategy. Harvard Bus Rev 65(3):43-59

Potdar PK, Routroy S, Behera A (2017a) Agile manufacturing: a systematic review of literature and implications for future research. Benchmark Int J 24(7):2022-2048. https://doi.org/10.1108/ BIJ-06-2016-0100

Potdar PK, Routroy S, Behera A (2017b) Analyzing the agile manufacturing barriers using fuzzy DEMATEL. Benchmark Int J 24(7):1912-1936. https://doi.org/10.1108/BIJ-02-2016-0024

Qing C, Shad D (2005) The impact of alignment between virtual enterprise and information technology on business performance in an agile manufacturing environment. J Oper Manag 23(5):531-550. https://doi.org/10.1016/j.jom.2004.10.010

Qin R, Nembhard DA (2010) Workforce agility for stochastically diffused conditions - a real options perspective. Int J Prod Econ 125(2):324-334. https://doi.org/10.1016/j.ijpe.2010.01.006

Quintana R (1998) A production methodology for agile manufacturing in a high turnover environment. Int J Oper Prod Man 18(5):452-470. https://doi.org/10.1108/01443579810206127

Rabah I, Said I, Mohamed AN (2015) Clustering-based urbanisation to improve enterprise information systems agility. Enterp Inform Syst 9(8):861-877. https://doi.org/10.1080/17517 575.2013.879210

Randolph J (2009) A guide to writing the dissertation literature review. Practl Assess Res Evaluat 14(13):1-13

Rao Y, Li P, Shao X, Shi K (2006) Agile manufacturing system control based on cell re-configuration. Int J Prod Res 44(10):1881-1905. https://doi.org/10.1080/00207540500410002

Rindova V, Kotha S (2001) Continuous 'morphing': competing through dynamic capabilities, form, and function. Acad Manag J 44(6):1263-1280. https://doi.org/10.5465/3069400

Sambamurthy V, Bharadwaj A, Grover V (2003) Shaping agility through digital options: reconceptualizing the role of information technology in contemporary firms. MIS Quart 27(2):237-263. https://doi.org/10.2307/30036530

Sanchez LM, Nagi R (2001) A review of agile manufacturing systems. Int J Prod Res 39(16):35613600. https://doi.org/10.1080/00207540110068790

Schirmer F, Ziesche K (2010) Dynamic Capabilities: Das Dilemma von Stabilität und Dynamik aus organisationspolitischer Perspektive. In: Barthel E, Haft A, Hasebrook J (eds) Integriertes Kompetenzmanagement im Spannungsfeld von Innovation und Routine. Waxmann, Münster/ New York/München/Berlin, pp 14-41

Sharifi H, Zhang Z (1999) A methodology for achieving agility in manufacturing organisations: an introduction. Int J Prod Econ 62(1-2):7-22. https://doi.org/10.1016/S0925-5273(98)00217-5

Sharifi H, Zhang Z (2001) Agile manufacturing in practice-application of a methodology. Int J Oper Prod Man 21(5-6):772-794. https://doi.org/10.1108/01443570110390462 
Sharp JM, Irani Z, Desai S (1999) Working towards agile manufacturing in the UK industry. Int J Prod Econ 62(1-2):155-169. https://doi.org/10.1016/S0925-5273(98)00228-X

Shin H, Lee JN, Kim D, Rhim H (2015) Strategic agility of Korean small and medium enterprises and its influence on operational and firm performance. Int J Prod Econ 168:181-196. https://doi. org/10.1016/j.ijpe.2015.06.015

Sieger DB, Badiru AB, Milatovic M (2000) A metric for agility measurement in product development. IIE Trans 32(7):637-645. https://doi.org/10.1080/07408170008967422

Sindhwani R, Malhotra V (2017) A framework to enhance agile manufacturing system: a total interpretive structural modelling (TISM) approach. Benchmark Int J 24(2):467-487. https://doi. org/10.1108/BIJ-09-2015-0092

Steinmann H, Schreyögg G, Koch J (2013) Management, 7th edn. Gabler Verlag, Wiesbaden

Subramaniam M, Youndt MA (2005) The influence of intellectual capital on the types of innovative capabilities. Acad Manag J 48(3):450-463. https://doi.org/10.5465/amj.2005.17407911

Sumukadas N, Sawhney R (2004) Workforce agility through employee involvement. IIE Trans 36(10):1011-1021. https://doi.org/10.1080/07408170490500997

Tallon PP, Pinsonneault A (2011) Competing perspectives on the link between strategic information technology alignment and organizational agility: insights from a mediation model. MIS Quart 352:463-486

Teece DJ, Pisano G, Shuen A (1997) Dynamic capabilities and strategic management. Strateg Manag J 18(7):509-533. https://doi.org/10.1002/(sici)1097-0266(199708)18:7\%3c509:aid-smj88 $2 \% 3 e 3.0 . c o ; 2-z$

Teece DJ, Peteraf M, Leih S (2016) Dynamic Capabilities and organizational agility: risk, uncertainty, and strategy in the innovation economy. Calif Manag Rev 58(4):13-35. https://doi.org/10.1525/ cmr.2016.58.4.13

Tracey M, Vonderembse MA (1999) Manufacturing technology and strategy formulation: keys to enhancing competitiveness and improving performance. J Oper Manag 17(4):411-428. https:// doi.org/10.1016/s0272-6963(98)00045-X

Van Oosterhout M, Waarts E, van Hillegersberg J (2006) Change factors requiring agility and implications for IT. Eur J Inform Syst 15(2):132-145. https://doi.org/10.1057/palgrave.ejis.3000601

Van Oyen MP, Gel EGS, Hopp WJ (2001) Performance opportunity for workforce agility in collaborative and noncollaborative work systems. IIE Trans 33(9):761-777. https://doi. org/10.1080/07408170108936871

Vázquez-Bustelo D, Avella L, Fernández E (2007) Agility drivers, enablers and outcomes: empirical test of an integrated agile manufacturing model. Int J Oper Prod Man 27(12):1303-1332. https ://doi.org/10.1108/01443570710835633

Vickery SK, Droge C, Setia P, Sambamurthy V (2010) Supply chain information technologies and organisational initiatives: complementary versus independent effects on agility and firm performance. Int J Prod Res 48(23):7025-7042. https://doi.org/10.1080/00207540903348353

Vinodh S (2010) Improvement of agility and sustainability: a case study in an Indian rotary switches manufacturing organisation. J Clean Prod 18(10-11):1015-1020. https://doi.org/10.1016/j.jclep ro.2010.02.018

Vinodh S, Aravindraj S (2015) Benchmarking agility assessment approaches: a case study. Benchmark Int J 22(1):2-17. https://doi.org/10.1108/bij-04-2013-0037

Vinodh S, Sundararaj G, Devadasan SR, Maharaja R, Rajanayagam D, Goyal SK (2008) DESSAC: a decision support system for quantifying and analysing agility. Int J Prod Res 46(23):6759-6780. https://doi.org/10.1080/00207540802230439

Vinodh S, Devadasan SR, Vasudeva Reddy B, Ravichand K (2010a) Agility index measurement using multi-grade fuzzy approach integrated in a 20 criteria agile model. Int J Prod Res 48(23):71597176. https://doi.org/10.1080/00207540903354419

Vinodh S, Sundararaj G, Devadasan SR, Kuttalingam D, Rajanayagam D (2010b) Amalgamation of mass customisation and agile manufacturing concepts: the theory and implementation study in an electronics switches manufacturing company. Int J Prod Res 48(7):2141-2164. https://doi. org/10.1080/00207540802456257

Vinodh S, Aravindraj S (2012) Agility evaluation using the IF-THEN approach. Int J Prod Res 50(24):7100-7109. https://doi.org/10.1080/00207543.2011.627390

Vinodh S, Aravindraj S, Pushkar B, Kishore S (2012a) Estimation of reliability and validity of agility constructs using structural equation modelling. Int J Prod Res 50(23):6737-6745. https://doi. org/10.1080/00207543.2011.623246 
Vinodh S, Madhyasta UR, Praveen T (2012b) Scoring and multi-grade fuzzy assessment of agility in an Indian electric automotive car manufacturing organisation. Int J Prod Res 50(3):647-660. https://doi.org/10.1080/00207543.2010.543179

Wang A, Koc B, Nagi R (2005a) Complex assembly variant design in agile manufacturing. Part I: system architecture and assembly modeling methodology. IIE Trans 37(1):1-15. https://doi. org/10.1080/07408170590516764

Wang A, Koc B, Nagi R (2005b) Complex assembly variant design in agile manufacturing. Part II: assembly variant design methodology. IIE Trans 37(1):17-33. https://doi.org/10.1080/07408 170590516773

Wang Z, Pan SL, Ouyang TH, Chou TC (2014) Achieving IT-enabled enterprise agility in China: an IT organizational identity perspective. IEEE Trans Eng Manag 61(1):182-195. https://doi. org/10.1109/tem.2013.2259494

Weber Y, Tarba SY (2014) Strategic agility: a state of the art. Calif Manag Rev 56(3):5-12. https:// doi.org/10.1525/cmr.2014.56.3.5

Yao AC, Carlson JGH (2003) Agility and mixed-model furniture production. Int J Prod Econ 81-82:95-102. https://doi.org/10.1016/s0925-5273(02)00359-6

Yusuf YY, Sarhadi M, Gunasekaran A (1999) Agile manufacturing: the drivers, concepts and attributes. Int J Prod Econ 62(1-2):33-43. https://doi.org/10.1016/S0925-5273(98)00219-9

Yusuf YY, Adeleye EO (2002) A comparative study of lean and agile manufacturing with a related survey of current practices in the UK. Int J Prod Res 40(17):4545-4562. https://doi. org $/ 10.1080 / 00207540210157141$

Zahra SA, Covin JG (1995) Contextual influences on the corporate entrepreneurship-performance relationship: a longitudinal analysis. J Bus Venturing 10(1):43-58. https://doi.org/10.1016/08839026(94)00004-e

Zahra SA, George G (2003) Absorptive capacity: a review, reconceptualization and extension. Acad Manag Rev 27(2):185-203. https://doi.org/10.5465/amr.2002.6587995

Zandi F, Tavana M (2011) A fuzzy group quality function deployment model for e-CRM framework assessment in agile manufacturing. Comput Ind Eng 61(1):1-19. https://doi.org/10.1016/j. cie.2011.02.004

Zhang DZ (2011) Towards theory building in agile manufacturing strategies-case studies of an agility taxonomy. Int J Prod Econ 131(1):303-312. https://doi.org/10.1016/j.ijpe.2010.08.010

Zhang Z, Sharifi $\mathrm{H}$ (2000) A methodology for achieving agility in manufacturing organisations. Int $\mathbf{J}$ Oper Prod Man 20(4):496-513. https://doi.org/10.1108/01443570010314818

Zhang Z, Sharifi H (2007) Towards theory building in agile manufacturing strategy-a taxonomical approach. IEEE T Eng Manag 54(2):351-370. https://doi.org/10.1109/tem.2007.893989

Publisher's Note Springer Nature remains neutral with regard to jurisdictional claims in published maps and institutional affiliations.

\section{Affiliations}

\section{Anna-Theresa Walter ${ }^{1}$}

1 Chair of Business Management, Esp. Organization, Technical University Dresden, 01062 Dresden, Germany 